\title{
Reseña de sentencias del Tribunal Constitucional sobre la Administración Local y Autonómica que aparecen publicadas en el BOE durante el segundo semestre de 1996
}

\author{
Francisco Javier Fernández González \\ Profesor Titular de Derecho Administrativo \\ Universidad de Oviedo
}

Sumario: I. FUENTES: A) Supletoriedad del Derecho estatal. B) Normas básicas. II. DEFENSOR DEL PUEBLO. SÍNDICO DE AGRAVIOS. III. EMPLEO PÚBLICO. IV. CONFLICTOS DE COMPETENCIAS ENTRE COMUNIDADES AUTÓNOMAS. V. JURISDICCIÓN CONTENCIOSO-ADMINISTRATIVA. VI. RECURSO DE AMPARO. CAUSAS DE INADMISION. VII. ACTIVIDAD ADMINISTRATIVA SANCIONADORA. VIII. AGUAS. IX. DERECHO PÚBLICO DE LA ECONOMÍA: A) Presupuestos Generales. B) Pesca. C) Energía. D) Entidades de Crédito. E) Transportes Terrestres. F) Publicidad. X. TRÁFICO, CIRCULACIÓN DE VEHICULOS Y SEGURIDAD VIAL. XI. CULTURA. XII. UNIVERSIDADES.

\section{FUENTES}

\section{A) Supletoriedad del Derecho estatal}

1. Recursos de inconstitucionalidad, acumulados, núms. 1191/1987, 1390/1987, 1391/1987 1392/1987 y 1393/1987, interpuestos, respectivamente, por el Presidente del Gobierno contra determinados preceptos de la Ley 12/1987, de 25 de mayo, del Parlamento de Cataluña, sobre regulación del Transporte de Viajeros por Carretera mediante vehículos de motor; por el Consejo Ejecutivo de la Generalidad de Cataluña contra la totalidad, con excepción de determinados artículos, de la Ley 16/1987, de 30 de julio, de Ordenación de los Transportes Terrestres; por el Consejo Ejecutivo de la Generalidad de Cataluña contra determinados artículos de la Ley Orgánica 5/1987, de 30 de julio, de Delegación de facultades del Estado en las Comunidades Autónomas, en relación con los Transportes por carretera y por cable; por el Parlamento de Cataluña contra determinados artículos de la Ley 16/1987, de 30 de julio, de Ordenación de los Transportes Terrestres; y, por último, por el Parlamento de Cataluña contra determinados artículos de la Ley Orgánica 5/1987, antes citada. El Tribunal estima parcialmente los recursos y declara la inconstitucionali- 
dad y, por consiguiente, la nulidad de determinados preceptos, asi como el carácter básico y la conformidad al orden constitucional de competencias de otras.

«Esta cuestión exige un análisis del significado de la previsión contenida en el art. 149.3 CE al disponer que "el Derecho estatal será, en todo caso, supletorio del Derecho de las Comunidades Autónomas" (...) La necesidad de garantizar la plenitud del ordenamiento, dado que el ejercicio pleno de las distintas competencias es un proceso que, ineluctablemente, se prolonga en el tiempo, determinó, como veremos inmediatamente, un entendimiento de la supletoriedad condicionado por la situación embrionaria del Estado de las Autonomías» (vid. f.j. 4).

«En efecto, desde la inicial STC 5/1981, fundamento jurídico 23, este Tribunal mantuvo una interpretación de la cláusula de supletoriedad orientada a potenciarla para que pudiese cumplir su fin, que consiste en "evitar vacíos en el sistema normativo de nuestro Estado autonómico" (STC 62/1990, fundamento jurídico $10, a .5$ ).

No obstante, esa potenciación de la supletoriedad no desconoció su esencia, pues nuestra jurisprudencia ha advertido expresamente que el último inciso del art. 149.3 CE no es, en manera alguna, "una cláusula universal atributiva de competencias sobre cualesquiera materias a favor del Estado" (SSTC 15/1989, fundamento jurídico $1 .^{\circ} ; 103 / 1989$, fundamento jurídico $4 .^{\circ}$ y 79/1992, fundamento jurídico $\left.3 .^{\circ}\right)$. Significativamente, la primera sentencia que explicitó esta idea lo hizo para negar que el Estado pudiera dictar una Ley general de defensa de los consumidores y usuarios, si carecía de toda competencia en la materia; y expresamente rechazó una determinada interpretación de la cláusula de supletoriedad que, en términos generales, hubiera dado por sí misma cobertura suficiente a la Ley impugnada, de manera que ésta, siempre y en todo caso, sería válida, aunque quedara desprovista de eficacia directa en aquellos ámbitos territoriales en los que las correspondientes Comunidades Autónomas hubieran ejercitado las competencias .legislativas que, sobre la materia "defensa de los consumidores y usuarios", constitucional y estatutariamente hubieran asumido (STC 15/1989, fundamento jurídico $1 .^{\circ}$ ).

En esa misma sentencia se explicitó la razón por la cual el Tribunal ha venido salvando la validez de numerosas disposiciones estatales, a pesar de haber sido dictadas en ámbitos asumidos como competencia exclusiva por Comunidades Autónomas promotoras de recursos de inconstitucionalidad o conflictos de competencia, respecto a las cuales esas disposiciones eran declaradas meramente inaplicables o aplicables en grado supletorio, pero no inválidas o nulas. 
RESEÑA DE SENTENCLAS DE. TRIBUNAL CONSTITUCIONAL ..

La razón estriba, simplemente, en que el Tribunal partía de una premisa determinada: la "potencial heterogeneidad" que tienen, en el sistema español, los ámbitos competenciales de las distintas Comunidades Autónomas (STC 53/1988, fundamento jurídico $1^{\circ} .^{\circ}$, esto es, los "diferentes niveles competenciales" en una materia entre unas y otras Comunidades Autónomas (SSTC 15/1989, fundamento jurídico $1 .^{\circ}$, in fine, $214 / 1989$, fundamento jurídico 30 ).

Por ende, pareció razonable admitir la existencia de normas estatales de valor supletorio, siempre que la materia competencial en litigio no hubiera sido "competencialmente asumida por todas las Comunidades Autónomas en términos de identidad u homogeneidad, por lo que todas aquellas competencias no atribuidas estatutariamente a las Comunidades Autónomas por imposibilidad constitucional, o por simple decisión de los propios Estatutos, habrán sido retenidas por el Estado en virtud del art. 149.3 CE, segundo inciso". Así fue posible que la Ley general de defensa de los consumidores y usuarios fuera juzgada constitucional, "ya que al no estar comprendida (dicha materia) ni en el art. 148.1, ni en el art. 149.1, ambos de la CE, sólo las Comunidades Autónomas no limitadas competencialmente por el primero de los referidos artículos han podido asumir competencias normativas plenas en dicha materia, correspondiendo al Estado su ejercicio en relación a todos los demás territorios autonómicos, lo que justifica la promulgación por el Estado de una Ley en el ejercicio de la competencia que le es propia sobre defensa de los consumidores y usuarios, sin perjuicio de que la aplicabiblidad y eficacia de la misma no alcance por igual a todo el territorio nacional" (en el mismo sentido, SSTC $5 / 1981,69 / 1982,227 / 1988,64 / 1989,133 / 1990,147 / 1991$ y $79 / 1992$ ).

Sólo en la STC 103/1989 se admitió que el Estado, en virtud de la cláusula que analizamos, pudiese dictar Derecho supletorio en materias atribuidas, en régimen de competencia exclusiva, a una o incluso a todas las Comunidades Autónomas [fundamento jurídico $4^{\circ}$, a)], pronunciamiento que fue corregido ulteriormente por las SSTC 214/1989, 133/1990 y 147/1991» (f.j. 5).

«Esta última resolución indica ya que la premisa de que, en numerosas materias, hay Comunidades Autónomas distintas a la que impugna una disposición estatal, que carecen de competencias, va siendo debilitada por el progresivo desarrollo del Estado de las Autonomías, prefigurado por el Título VIII de la Constitución. Existen numerosas materias atribuidas por los Estatutos de Autonomía a la competencia exclusiva de todas y cada una de las Comunidades Autónomas, lo cual impide al Estado dictar disposiciones en dichas materias, "puesto que la asunción de competencias exclusivas confiere a las Comunidades Autónomas no sólo el poder oponerse a que las normas del Estado incidan en esas materias sometidas a su competencia exclusiva con alcance de aplicación directa, sino que también atribuyen a las Comunidades decidir si tales ma- 
terias deben ser sometidas, por su parte, a reglamentación específica y en qué momento debe hacerse" (fundamento jurídico $7 .^{\circ}$ ).

De aquí se desprenden unas conclusiones inequívocas. La primera, que la supletoriedad del Derecho estatal ha de ser inferida por el aplicador del Derecho autonómico, mediante el uso de las reglas de interpretación pertinentes, y por imperativo de la última frase del art. 149.3 CE. "Para armonizar de manera congruente" las "distintas declaraciones doctrinales integrándolas en un sistema conceptual dotado del grado de coherencia que le es exigible", sigue afirmando la STC 147/1991, es preciso "reducir el concepto de supletoriedad a sus correctos términos de función, cuya operatividad corresponde determinarse (sic) a partir de la norma reguladora del ámbito material en el que se va a aplicar el Derecho supletorio y no desde éste, es decir, como función referida al conjunto del ordenamiento jurídico, cuyo valor supletorio debe obtenerse por el aplicador del Derecho a través de las reglas de interpretación pertinentes, incluida la vía analógica, y no ser impuesta directamente por el legislador desde normas especialmente aprobadas con tal exclusivo propósito, para incidir en la reglamentación jurídica de sectores materiales en los que el Estado carece de título competencial específico que justifique dicha reglamentación". La segunda, que el Estado no puede dictar normas con eficacia meramente supletoria, en materias sobre las cuales carece de todo título competencial; el legislador estatal no puede apoyarse en la regla de la supletoriedad para dictar tales normas, por no constituir una cláusula universal atributiva de competencias.

Tales afirmaciones llevaron a la STC 147/1991 a mantener, como corolario, una doctrina fundamental de la que debemos partir: "Lo expuesto conduce en principio a considerar viciadas de incompetencia y, por ello, nulas las normas que el Estado dicte con el único propósito de crear Derecho supletorio del de las Comunidades Autónomas en materias que sean de la exclusiva competencia de éstas, lo cual no es constitucionalmente legítimo cuando todos los Estatutos de Autonomía atribuyen a las Comunidades la competencia como exclusiva y en un mismo grado de homogeneidad" (fundamento jurídico $7 .^{\circ} .7$ ).

Esa tesis, reiterada luego en la SSTC 79/1992 (fundamento jurídico $3 .^{\circ}$ ) y 213/1994 (fundamento jurídico $4 .^{\circ}$ ), se entendía, sin embargo, compatible con la posibilidad de que el Estado dictase normas de carácter meramente supletorio allí donde ostentase competencias en la materia (vgr., para regular lo básico).

Y éste es el punto que debemos revisar ahora. La cláusula de supletoriedad es, según la doctrina expuesta, una previsión constitucional emanada de la CE 
RESEÑA DE SENTENCIAS DEL TRIBUNAL CONSTTTUCIONAL ..

que se dirige al aplicador del Derecho, indicándole el modo en que deben colmarse las lagunas del ordenamiento autonómico, cuando las haya.

A tenor de la misma una vez que el aplicador del Derecho, utilizando los medios usuales de interpretación, haya identificado una laguna en el ordenamiento autonómico, deberá colmarla acudiendo a las normas pertinentes, dictadas por el Estado en el ejercicio de las competencias que la Constitución le atribuye: en eso consiste la supletoriedad del Derecho estatal que, por su misma naturaleza, no comporta atribución competencial alguna.

Por eso, para que el Estado pueda dictar normas jurídicas que regulen una materia determinada, no basta con que ostente un título que le atribuya cualesquiera competencias en esa materia, sino que debe poder invocar aquel título específico que le habilite en concreto para establecer la reglamentación de que se trate, sin que, como correctamente se afirmaba en la STC $147 / 1991$, que acabamos de transcribir, pueda invocar como tal la cláusula de supletoriedad.

Aquí se trata sólo, por lo tanto, de extraer las consecuencias lógicas de tal afirmación, que entonces no llegaron a formularse: si para dictar cualesquiera normas precisa el Estado de un título competencial específico que las justifique, y la supletoriedad no lo es, esa conclusión ha de mantenerse en todo caso. Por lo tanto, tampoco en las materias en las que el Estado ostenta competencias compartidas puede, excediendo el tenor de los títulos que se las atribuyen y penetrando en el ámbito reservado por la Constitución y los Estatutos a las Comunidades Autónomas, producir normas jurídicas meramente supletorias, pues tales normas, al invocar el amparo de una cláusula como la de supletoriedad que, por no ser título competencial, no puede dárselo, constituyen una vulneración del orden constitucional de competencias» (f.j. 6).

«Nuestra jurisprudencia sobre la cláusula de supletoriedad cobra todo su valor en una materia como la que centra el presente proceso constitucional. Los transportes terrestres están confiados a la competencia exclusiva de la Comunidad Autónoma de Cataluña cuando los itinerarios se desarrollan íntegramente en su territorio; por el contrario, corresponden a las instituciones generales del Estado cuando transcurren por el territorio de inás de una Comunidad Autónoma, como vimos.

Junto a este dato, no es posible ignorar que todas las Comunidades Autónomas han asumido competencia exclusiva en materia de transportes intracomunitarios ... Lo cual forma parte de la lógica institucional del modelo de Estado diseñado por el Título VIII de la Constitución, ya que esta competencia se encuentra expresamente recogida en su art. 148.1, que enumera las competencias 
que forman con naturalidad el núcleo del ámbito de autonomía reconocido constitucionalmente a todas las Comunidades Autónomas.

Y a ello se añade cuanto acaba de afirmarse, a saber: que la supletoriedad no es, en ningún caso, título competencial.

Por consiguiente, es indudable que en materia de transportes terrestres el Estado no puede dictar normas puramente supletorias, dirigidas exclusivamente a regular aquellos transportes que se encuentran sometidos a la competencia exclusiva de las Comunidades Autónomas. En la medida en que las normas que resulten de aplicación a los transportes terrestres intracomunitarios, en cada una de las Comunidades Autónomas, ofrezcan lagunas, los aplicadores del Derecho deberán integrarlas de conformidad con las reglas usuales de interpretación, incluida la cláusula de supletoriedad del Derecho estatal del art. 149.3, in fine, CE. Pero la supletoriedad resultará predicable, por disponerlo así la Norma fundamental, de las normas dictadas válidamente por el Estado en materias de su competencia: ya los preceptos sobre transportes intercomunitarios, ya los preceptos aplicables a los transportes de competencia autonómica, pero fundados en títulos competenciales del Estado distintos al de "transporte", sin que ello implique la aplicación de dichos preceptos ante la simple ausencia de regulación autonómica en la materia de que se trate; la aplicación de los preceptos aludidos como supletorios dependerá de la eventual identificación de una laguna por el aplicador del derecho» (vid. f.j. 7).

Fallo: Vid. infra, Derecho Público de la Economía: Transportes Terrestres.

(Sentencia n. $.^{\circ} 18 / 1996$, de 27 de junio. Pleno. BOE 29 de julio de 1996. TS Vives Antón. Voto particular formulado por M. Jiménez de Parga y Cabrera).

\section{B) Normas básicas}

1. Conflicto positivo de competencia núm. 1715/1991, promovido por el Consejo Ejecutivo de la Generalidad de Cataluña en relación con el art. 1 y la Disposición adicional primera del Real Decreto 557/1991, de 12 de abril (BOE núm. 95, de 20 de abril), sobre creación y reconocimiento de Universidades y Centros universitarios, en cuanto califican como normas básicas varios preceptos del citado Real Decreto. El TC estima parcialmente el conflicto y entiende que no son normas básicas determinados preceptos impugnados.

«El Consejo Ejecutivo de la Generalidad de Cataluña sostiene en su demanda que los preceptos del Real Decreto 557/1991 a los que se ha hecho referencia 
en los Antecedentes de esta sentencia no pueden tener, como pretende el Gobierno de la Nación, el carácter de normas básicas. De un lado, por carecer del rango legal propio y necesario de la normación básica; de otro, y con carácter general, por tratarse de preceptos que especifican y concretan hasta tal punto las condiciones impuestas a la creación y reconocimiento de Universidades y Centros universitarios que vacían por completo de contenido las competencias atribuidas constitucional y estatutariamente a la Generalidad de Cataluña, lo que no se compadece, en absoluto, con la noción de normas básicas.

El Abogado del Estado, por su parte, opone a lo anterior, en defensa de la calificación como básicas de las normas impugnadas, que, de acuerdo con reiterada doctrina de este Tribunal, es perfectamente admisible la normación básica a través de normas infralegales y, además, que, atendidas las competencias estatales ex art. 149.1.1 y $30 \mathrm{CE}$, los preceptos objeto de conflicto no hacen sino sentar las bases sobre una materia de la competencia del Estado sin privar por ello a la Generalidad de Cataluña de la posibilidad de ejercer las competencias de desarrollo que le corresponden de conformidad con la Constitución y su Estatuto» (f.j. 1).

«En relación con la primera de las objeciones que, con carácter general, opone el Consejo Ejecutivo a la constitucionalidad del Real Decreto 557/1991, esto es, la referida a la insuficiencia de rango de los preceptos que el Gobierno de la Nación ha calificado de básicos, este Tribunal ha declarado en múltiples ocasiones que para garantizar la generalidad y estabilidad consustanciales a las reglas básicas (STC 147/1991, éstas deben establecerse mediante ley formal votada en Cortes, aunque, como excepción, quepa admitir que en ciertas circunstancias el Gobierno pueda regular por Real Decreto aspectos básicos de una determinada materia. Estas circunstancias excepcionales se dan, según hemos reiterado, cuando el reglamento resulta "complemento indispensable" para asegurar el mínimo común denominador establecido en las normas legales básicas (por todas SSTC 25/1983, 32/1983 y 48/1988): es indispensable cuando la ley formal no resulta instrumento idóneo para regular exhaustivamente todos los aspectos básicos, debido al "carácter marcadamente técnico o a la naturaleza coyuntural y cambiante" de los mismos (SSTC 76/1983, 87/1985, 86/1989, $147 / 1991$ y 149/1992, entre otras), y es complemento de las normas legales básicas, cuando, además de ser materialmente básico, actúa como desarrollo de una ley que previamente ha acotado el alcance general de lo básico ("el Gobierno puede regular por vía reglamentaria materias básicas definidas como tales en normas de rango de ley, porque entonces su actuación es completiva y no delimitativa o definidora de competencias" [SSTC 25/1983, 32/1983 y 42/1983, entre otras]). Por otra parte, desde la perspectiva formal, se ha exigido también que el carácter básico se explicite bien en la ley básica de la que 
trae causa el reglamento, bien en la propia disposición infralegal. La declaración del carácter básico "no es una posibilidad abierta al titular de la potestad normativa (...), sino un deber general inherente a su función" (STC 175/1992). Sólo cabe reconocer el carácter básico implícito a disposiciones de rango infralegal cuya naturaleza básica resulta "sin lugar a dudas de su propia estructura normativa en cuanto complemento indispensable de las normas legales básicas".(STC 227/1988), en el mismo sentido, entre otras, STC 15/1989).

Pues bien, en el presente caso, y a reserva de lo que resulte del examen pormenorizado de cada uno de los preceptos controvertidos, puede avanzarse ya que el Real Decreto 557/1991 pretende actuar como complemento básico indispensable de unos preceptos de una ley -la Ley Orgánica 11/1983, de Reforma Universitaria-, calificados como básicos, que explícitamente habilitan al Gobierno para llevar a cabo esta tarea de desarrollo reglamentario relativo a cuestiones consideradas, por su detallismo y su carácter técnico, impropias de una ley. Por otra parte, en cuanto al requisito formal, los preceptos impugnados han sido explícitamente declarados básicos por la Disposición adicional primera del Real Decreto enjuiciado.

Habrá de verse, claro está, si los concretos preceptos objeto de conflicto se ajustan a lo que ha de ser su cometido, esto es, a la delimitación última y por supuesto básica de unas bases que, en lo fundamental, han sido ya sentadas por el Estado en aquella Ley Orgánica. Sin embargo, en este momento debe rechazarse la objeción global formulada por la actora» (f.j. 2).

Fallo: Vid. infra: Universidades.

(Sentencia n. ${ }^{\circ} 131 / 1996$, de 11 de julio. Pleno. BOE 12 de agosto de 1996. C.Viver Pi-Sunyer. Voto particular formulado por J. D. González Campos, al que se adhiere M. Jiménez de Parga y Cabrera).

2. Conflicto positivo de competencia núm. 329/1989, promovido por el Consejo Ejecutivo de la Generalidad de Cataluña, contra el Real Decreto 1122/1988, de 23 septiembre del Ministerio de Relaciones con las Cortes y de la Secretaría del Gobierno, por el que se aprueba la Norma General de etiquetado, presentación y publicidad de los productos alimenticios envasados, cuyo artículo 19 aprobado por el artículo único del RD 1122/1988 dispone, como precepto con carácter básico, que «los datos obligatorios del etiquetado de los productos alimenticios que se comercialicen en España se expresarán necesariamente al menos en la lengua española oficial del Estado». La Comunidad Autónoma de Cataluña entiende que este precepto no puede considerarse como básico y vulnera las competencias autonómi- 
RESEÑA DE SENTENCLAS DEL TRIBUNAL CONSTITUCIONAL ..

cas. El Tribunal declara que la competencia controvertida corresponde al Estado.

«La última cuestión que el presente conflicto plantea es la relativa a los requisitos formales de una norma estatal como la impugnada, dictada al amparo de la competencia sobre "bases y coordinación general de la sanidad". A cuyos efectos es de tener en cuenta que la doctrina general sobre la dimensión formal de las "bases", como competencia normativa estatal, fue muy particularmente formulada con ocasión del conflicto que resulta ser el antecedente inmediato del que ahora nos ocupa, es decir, en la STC 69/1988.

De conformidad con dicha doctrina, es preciso que "las "bases" se regulen, en principio, por Ley formal", aun cuando "es admisible, como excepción, que el Gobierno de la Nación pueda regular por Decreto alguno de los aspectos básicos de una materia cuando resultan complemento necesario para garantizar el fin a que responde la competencia estatal sobre las bases" (STC 248/1988, fundamento jurídico $4 .^{\circ}$ ). Esa excepción se justifica muy especialmente "en el caso de la legislación preconstitucional $\longrightarrow$ anterior a la aprobación de los Estatutos de Autonomía-, es decir, en aquellos supuestos en que no le era posible al Estado prever la ulterior atribución de competencias a las Comunidades Autónomas y desplegar la correspondiente actividad legislativa de delimitasen de lo básico" (ibid.); pero no sólo se justifica entonces, pues es perfectamente posible que, en el marco de la colaboración entre la ley y el reglamento, se haga necesaria la intervención de este último a los fines de perfilar la acabada delimitación material de las bases, que ha debido encontrar en aquélla su definición más sustantiva. Como con carácter general tenemos dicho respecto de la legitimidad constitucional de las habilitaciones legales en favor de la potestad reglamentaria, también aquí esas remisiones son únicamente admisibles si restringen efectivamente el ejercicio de esa potestad a un complemento de la regulación legal que sea indispensable por motivos técnicos o para optimizar el cumplimiento de las finalidades propuestas por la Constitución o por la propia ley (SSTC 83/1984, 137/1986, 178/1989, 225/1993). En ningún caso con todo, la habilitación puede serlo para el desarrollo de lo básico, sino, estrictamente, para la definición última de la normación básica, cuyo desarrollo puede haberse erigido en competencia autonómica.

Siendo ello así, es preciso examinar si el art. 19 de la Norma General representa un supuesto constitucionalmente admisible, en materia de definición de lo básico, de colaboración entre la ley y el reglamento, pues es obvio que la exigencia referida a la definición expresa de su condición de norma básica se cumple sobradamente en la Disposición adicional del Real Decreto. En otras palabras, procede verificar si el repetido art. 19 satisface las condiciones formales de lo básico, no tanto por lo que afecta a la exigencia de su expresa cali- 
ficación como norma básica, como en lo que se refiere a la necesidad de que, por principio, lo básico se defina y establezca en normas con forma de ley.

Mientras el Consejo Ejecutivo sostiene que el precepto que ha suscitado el presente conflicto no encuentra cobertura en ninguna ley del Estado dictada en ejercicio de la competencia reservada en el art. 149.1.16. ${ }^{\mathrm{a}}$ de la Constitución, el Abogado del Estado entiende, por el contrario, que tal cobertura le viene brindada por la Ley 26/1984, General para la Defensa de los Consumidores y Usuarios, cuyo art. 4.1 e), encuadrado en el Capítulo Segundo ("Protección de la salud y seguridad"), se refiere al "etiquetado, presentación y publicidad" como una de las determinaciones que, "al menos" deben contener "los reglamentos reguladores de los diferentes productos, actividades o servicios", en tanto que el art. 4.3 añade que "los extremos citados podrán ser objeto de codificación mediante normas comunes o generales", especialmente en ciertas materias, entre las que se enumera el etiquetado.

En relación con la habilitación contenida en el art. 4.3 de la Ley $26 / 1984$, dijimos en la STC 15/1989 que cabe entender que responde a la finalidad de coordinación que en materia sanitaria corresponde al Estado (art. 149.1.16. $\mathrm{CE}$ ), entendiéndose por coordinación, entre otras manifestaciones, "la fijación de medios (...) que hagan posible (...) la homogeneidad técnica en determinados aspectos" (entre otras, en relación con la sanidad, STC 32/1983, fundamento jurídico $2 .^{\circ}$ ), lo que, en el presente caso, pudiera articularse mediante la aprobación de normas comunes o generales, codificadoras de los extremos señalados. En última instancia, se trata de una previsión que en sí misma no menoscaba ni incide en las competencias de la Generalidad de Cataluña, y que, por tanto, no incurre en inconstitucionalidad, sin perjuicio, claro es, de la corrección con que el Estado pueda ejercitar esa competencia, en cuyo caso, contra las normas en que pueda materializarse, la Comunidad Autónoma podrá promover, obviamente, los procesos constitucionales en defensa de sus competencias» [fundamento jurídico $3 .^{\circ} \mathrm{b}$ )].

De lo que aquí se trata, precisamente, es de examinar si el etiquetado de los productos alimenticios puede venir o no disciplinado por una norma estatal en ejercicio del título competencial referido a la sanidad. Esto es, si la habilitación contenida en el art. 4.3 de la Ley 26/1984 y su ejercicio a través del Real Decreto $1122 / 1989$ configuran en su conjunto una norma merecedora de la condición de básica en materia sanitaria. La relación entre este Real Decreto y aquella Ley puede encuadrarse sin dificultad en el esquema propio de la colaboración entre la ley y el reglamento a los fines de la definición en su conjunto de una norma de carácter básico, pues el ejercicio de la potestad reglamentaria no ha producido otro resultado que el de haber dado cuerpo a un complemento de la regulación legal que resulta indispensable por evidentes motivos técnicos 
RESEÑA DE SENTENCIAS DE. TRIBUNAL CONSTTTUCIONAL ..

y que permite optimizar el cumplimiento de las finalidades propuestas por la propia Ley» (f.j. 7).

«En definitiva, el art. 19 de la Norma General aprobada por el Real Decreto $1122 / 1988$, a diferencia de lo que sucedía con el art. 20 de la aprobada por el Real Decreto 2058/1982 (STC 69/1988), reúne las condiciones formales necesarias a los efectos de su calificación como norma básica, siendo materialmente encuadrable en la competencia exclusiva estatal sobre bases y coordinación general de la sanidad (art. 149.1.16. ${ }^{\mathrm{a}}$, inciso segundo, CE) dada la trascendencia para la salud de los consumidores de la disciplina que en la misma se establece» (f.j. 8).

Fallo: Declarar que la competencia controvertida corresponde al Estado.

(Sentencia n. ${ }^{\circ}$ 147/1996, de 19 de septiembre. Pleno. BOE 5 de noviembre de 1996. P. Cruz Villalón. Votos particulares formulados, el primero, por C. Viver Pi-Sunyer, al que se adhiere V. Gimeno Sendra, y, el segundo, por J. D. González Campos).

\section{DEFENSOR DEL PUEBLO. SÍNDICO DE AGRAVIOS}

1. Recurso de inconstitucionalidad núm. 580/1989, interpuesto por el Presidente del Gobierno contra el art. 24.2 de la Ley de la Comunidad Valenciana 11/1988, de 26 de diciembre, del Síndico de Agravios, que otorga una protección penal específica a la función investigadora del Síndico de Agravios, calificando como delito de desobediencia ciertas conductas en relación con el envío de los informes o datos que hubiese solicitado. El TC estima el recurso y declara la inconstitucionalidad y nulidad del mencionado precepto por invadir la competencia exclusiva del Estado en materia de legislación penal.

«Nos hallamos ante una Ley autonómica que reproduce un precepto de la Ley Penal y, además, introduce al hacerlo alguna modificación en el tipo formulado por el Código y por la Ley 3/1981, de 6 de abril, del Defensor del Pueblo (art. 24.2). Modificación que, se limite o no a constituir, como se alega, una interpretación, al agregar al mismo las especificaciones que agrega, viene en realidad a formular un tipo penal de la desobediencia cuando ésta tiene lugar respecto a los actos del Síndico de Agravios valenciano de modo distinto al previsto en general por el Código Penal y en particular respecto del Defensor del Pueblo por su Ley particular (...). 
Si la reproducción de normas estatales por Leyes autonómicas es ya una técnica peligrosamente abierta a potenciales inconstitucionalidades, esta operación se convierte en ilegítima cuando las Comunidades Autónomas carecen de toda competencia para legislar sobre una materia (STC 35/1983)» (vid. f.j. 3).

«En el supuesto que ahora nos ocupa, es indudable que el precepto cuya constitucionalidad se cuestiona, merece ser calificado por sus contenidos como "legislación penal" puesto que se trata de la configuración de un tipo (correspondiente al delito de desobediencia); ámbito material éste que el art. 149.1.6 de la Constitución reserva a la competencia exclusiva del Estado y que, por tanto, está vedado al legislador autonómico.

Pero es que dicho precepto legal no se limita, como antes decimos, a una mera reproducción textual de lo dispuesto en el art. 24.2 de la Ley Orgánica del Defensor del Pueblo, sino que, además, incorpora ciertas modificaciones de redacción que, con independencia de su relevancia material, son palmaria manifestación de la acción del legislador autonómico en un ámbito -el de la legislación penal- que le está constitucionalmente proscrito, lo cual viene incluso corroborado por los argumentos de la contestación a la demanda del Presidente de las Cortes Valencianas quien alega que la modificación introducida en el precepto no crea una mera norma sino que viene a constituir una interpretación de la misma. Y más aún si se advierte que tal modificación no para en ello, puesto que al sustituir en el precepto reproducido la frase "negativa o negligencia en el envío de los informes que éste solicitó" por la expresión "negativas o dilaciones injustificadas en el envío de los informes o datos...", configura de hecho un tipo penal diferente, puesto que difieren el alcance de la expresión "negligencia" y el de las "dilaciones injustificadas" por la que se la sustituye.

De ahí que haya de estimarse que el art. 24.2 de la Ley $11 / 1988$ de la Comunidad Autónoma Valenciana invade la competencia exclusiva del Estado en materia de legislación penal y por ello ha de declararse su inconstitucionalidad. Lo cual hace innecesario el examen de los restantes argumentos aducidos por el Abogado del Estado en su escrito de interposición del recurso» (f.j. 4).

Fallo: Estimar el recurso de inconstitucionalidad interpuesto por el Presidente del Gobierno de la Nación contra el art. 24.2 de la Ley del Síndico de Agravios, 11/1988, de 26 de diciembre, de la Comunidad Valenciana y, en su consecuencia, declarar inconstitucional y nulo el mencionado precepto legal.

(Sentencia n..$^{\circ}$ 162/1996, de 17 de octubre. Pleno. BOE 5 de nc iembre de 1996. J. Gabaldón López). 
RESEÑA DE SENTENCIAS DEL TRIBUNAL CONSTITUCIONAL ..

\section{EMPLEO PÚBLICO}

1. Conflicto positivo de competencia núm. 407/1986, promovido por el Gobierno, frente al Consejo Ejecutivo de la Generalidad de Cataluña, en relación con los arts. 4 (apartados 2 y 3), 8, 9, 10, 11 (apartado 2 en su último inciso) y la Disposición adicional primera del Decreto 307/1985, de 31 de octubre, sobre normas y procedimiento para la aplicación de las incompatibilidades al personal sanitario al servicio de la Generalidad. El TC declara inconstitucionales los apartados segundo y tercero del art. 4, el art. 8.2, el inciso "a partir de la entrada en vigor del presente Decreto» del art. 9.1 y el art. 10 del mencionado Decreto.

«El conflicto positivo de competencia que nos ocupa ha surgido por la promulgación del Decreto 307/1985, de 31 de octubre, que dictó el Consejo de Gobierno de la Generalidad de Cataluña para regular, con carácter transitorio, provisional en suma, las incompatibilidades de su personal sanitario, en desarrollo y aplicación - según el preámbulo- de la Ley estatal 53/1984, de 26 de diciembre, donde se configura el régimen general de tales situaciones para todo el personal de las Administraciones, la primera de cuyas disposiciones finales declara el carácter básico de su contenido, a salvo las excepciones que en su texto se indican, que no hacen al caso. El Gobierno de la Nación opina que la disposición reglamentaria catalana excede las atribuciones propias de la Comunidad Autónoma, según son diseñadas por la Constitución, el Estatuto de Autonomía correspondiente y las normas básicas sobre la materia configuradas legalmente y, por ello, plantea la impugnación que es en definitiva, el objeto de este proceso. Con posterioridad a su incoación el Parlamento de Cataluña aprobó la Ley 21/1987, de 26 de noviembre, bajo la rúbrica de "incompatibilidades del personal al servicio de la Administración de la Generalidad", cuya constitucionalidad se ha puesto en tela de juicio, también, por el Presidente del Gobierno de la Nación, recurso de inconstitucionalidad núm. 399/1988 pendiente de ser resuelto» (vid. f.j. 1).

«Empezando por el principio, la Ley 53/1984 permite que el personal sanitario pueda compatibilizar la actividad asistencial o propia de su puesto de trabajo con determinadas plazas de carácter docente, "dentro del área de la especialidad del Departamento Universitario" (art. 4.2), cautela esta última -la entrecomillada - desaparecida en el correlativo del Decreto de la Generalidad (art. 4, apartados $2 .^{\circ}$ y $3 .^{\circ}$ ). Tal omisión, de la que se queja el Gobierno de la Nación, sólo alcanzaría significado constitucional si lo eliminado tuviera carácter básico, que no puede serle negado a la luz de las reflexiones más arriba hechas sobre su concepto. Efectivamente, el sistema de incompatibilidades en la función pública parte del "principio fundamental" (así calificado por el Preámbulo de 
la Ley 53/1984) de que cada funcionario desempeñe un puesto de trabajo para que su dedicación haga realidad la eficacia que de la actividad administrativa se predica constitucionalmente, como antes se dijo. Las excepciones a dicha regla, que responde en nuestro Derecho a una larga tradición jurídica (STC 68/1990), en cuanto eventualmente debiliten la antedicha aspiración constitucional han de configurarse de tal modo que respetan tales criterios. Pues bien, siendo básica tanto la regulación como las eventuales excepciones lo es también necesariamente la exigencia de requisitos o condicionamientos directamente conectados con aquélla o éstas y, en consecuencia, no pueden ser desconocidos por el desarrollo autonómico correspondiente.

Así pues, la exigencia de que ambos puestos de trabajo correspondan a una misma área científica, albergada en el Departamento correspondiente "órgano básico" en la estructura de las Universidades según el art. 8.1 de la Ley Orgánica 11/1983, de 25 de agosto para la reforma universitaria, pretende por una parte fomentar la especialización y, a través de ella, intensificar la preparación profesional del personal ahondando en sus dos vertientes teórica y práctica y evitando la dispersión, y aún la superficialidad de saberes en beneficio último de los eventuales pacientes y de la asistencia sanitaria a la comunidad en su conjunto. Por otra parte, esto mismo favorece indirectamente una mayor dedicación a ambos puestos de trabajo por su misma homogeneidad. Puede quedar encuadrado, pues, tal condicionamiento de la compatibilidad, sin violencia conceptual alguna, dentro del valor constitucional de la eficacia en el desempeño de la función pública como quedó sobredicho entroncando a su vez con el derecho de todos a la protección de la salud (art. 43.1 CE). En tal sentido no está de más advertir que tal cautela, eliminada en el Decreto, ha sido restituida al texto de la Ley catalana 21/1987.

Un paso más en este camino lleva de la mano a la conclusión, extraída de nuestro acervo doctrinal, de que omitir puede ser en ocasiones tanto como contradecir. En este caso el silencio sobre una condición básica para el sistema de incompatibilidades no puede calificarse como inocuo, indiferente o neutro. Ahora bien, una tal deficiencia podría quedar subsanada se dice por obra y gracia de las técnicas de integración normativa, ya que la segunda de las disposiciones adicionales del Decreto contiene una cláusula de cierre y seguridad cuando advierte que "en todo aquello no previsto en el presente Decreto serán de aplicación las normas contenidas en la Ley 53/1984". Sin embargo, no es suficiente. La incorporación íntegra de la norma básica ha de exigirse aquí y ahora por virtud del carácter esencial del requisito omitido. En consecuencia, no siendo posible una interpretación conforme del precepto reglamentario así mutilado, resulta clara su invalidez» (f.j. 2). 
RESEN̄A DE SENTENCIAS DEL TRIBUNAL CONSTITUCIONAL...

«Otra cuestión provoca una vez más el que la disposición reglamentaria catalana (el art. 8 del Decreto 307/1985) haya eliminado un supuesto de incompatibilidad previsto en el Real Decreto 598/1985, según alega el Gobierno de la Nación. Ahora bien, aquí se produce una visible desviación del planteamiento. En efecto, la norma que en todo momento orienta este debate constitucional desde su principio es y no puede ser otra que la Ley 53/1984, donde se contienen las normas básicas para la materia, única referencia válida. El Real Decreto $598 / 1985$ no participa de aquella consideración y, por tanto, carece de virtualidad para condicionar el desarrollo legislativo o reglamentario autonómico. Dicho esto, la prohibición de simultanear actividades privadas con las propias de su función pública comprende "las actividades profesionales prestadas a personas a quienes se está obligado a atender en el desempeño del puesto público" [art. 12.1 a) de la Ley]. Este enunciado genérico cuyos destinatarios son los funcionarios públicos en general sin distinción de profesiones, adquiere una mayor concreción para el personal sanitario sin alterar la esencia del mandato en el Real Decreto 598/1985 donde se prohíbe al personal sanitario de la Seguridad Social (no jerarquizado) el ejercicio de la actividad de carácter privado "respecto de las personas que se hallen incluidas en su correspondiente cupo". A su vez, el Decreto 307/1985 circunscribe el ámbito de la misma interdicción cuando se trate de "personas que sean atendidas, o bien lo hayan sido en el curso del mismo proceso patológico en el Hospital en que se desarrolle la actividad de carácter público".

La lectura de las normas sobredichas pone ya de relieve que el ámbito extenso por indefinido de la incompatibilidad configurada en la Ley estatal se reduce y constriñe en la disposición reglamentaria de la Generalidad, aun cuando ponga por delante una invocación a aquélla, con cita de su art. 12.1 a), como cláusula de estilo. La parte que tácitamente se cercena así no puede ser restituida al texto por reenvío a la regla de integración normativa contenida en la segunda de las Disposiciones adicionales del Decreto. Vale para el caso, sin necesidad de repetirlo, cuanto se dice al respecto en el último párrafo del segundo de los fundamentos jurídicos de esta nuestra sentencia» (f.j. 4).

«Más adelante, se denuncia por el Gobierno de la Nación una contradicción frontal entre el art. 9 del Decreto 307/1985 y la tercera de las Disposiciones transitorias de la Ley 53/1984 en un doble aspecto. Por una parte, el Gobierno de la Nación echa en falta una referencia cronológica cuando se trata de compatibilizar actividades públicas sanitarias, que los dos puestos de trabajo cuyo desempeño simultáneo se pretenda, vinieran siéndolo así antes de la entrada en vigor de la Ley estatal tantas veces mencionada. A su juicio, la redacción del precepto reglamentario en entredicho da pie a que puedan obtener la autorización para simultanear el desempeño de dos puestos de trabajo públicos en el sector sanitario, en régimen de prestación a tiempo parcial, quienes sin haberlo 
hecho así con anterioridad, empezaran a hacerlo después de la vigencia de la Ley. No es así, ni así lo parece siquiera de la lectura del texto, que no es problemático en este aspecto. Efectivamente, la frontera cronológica está nítidamente trazada por la remisión al "personal a que hace referencia la Disposición transitoria tercera de la Ley 53/1984", donde se regulan las distintas situaciones al respecto, sin alteración alguna. En consecuencia, no cabe achacarle ningún defecto, ni omisión alguna en este punto.

Por otra parte, la segunda quiebra de la misma disposición transitoria imputable - según se dice - a la reglamentaria, estriba en la modificación que ésta introduce en los plazos allí previstos para la aplicación gradual del sistema, irrespeto negado por la Generalidad para quien una norma de Derecho intertemporal no puede ser básica por impedirlo su propia esencia, por definición en expresión más llana y, en consecuencia, no existe obligación alguna de respetarla cuando se trata de su desarrollo. Un planteamiento tal no es de recibo. Una vez que se reconoce constitucionalmente al Estado una determinada competencia para establecer las bases en una materia cualquiera, no cabe desgajar de la regulación su elemento temporal, inherente a cualquier actividad humana $y$, por supuesto, a la legiferante. Las normas se dictan en un momento del tiempo, para hoy y para mañana, como también para una sociedad concreta arraigada en un ámbito territorial.

En tal sentido, hemos dicho años atrás que nada puede objetarse a que se regulen también como básicos, los aspectos transitorios del régimen correspondiente que también lo es (STC 133/1990). Siéndolo pues, como se ha explicado más atrás, el régimen de incompatibilidades de la función pública, lo es también la regulación del período intermedio, desde la vigencia formal de la Ley hasta la implantación plena del sistema que configure, marcando etapas mediante hitos cronológicos para pasar de un régimen al otro. Visto así el planteamiento, el art. 9 del Decreto sobrepasa los límites de la competencia de su autora, la Generalidad, desde el momento en que desplaza a la entrada en vigor de sí mismo los efectos que la Ley, en la tercera de sus Disposiciones transitorias, defiere al 1 de octubre de 1985 , en relación con la posibilidad de seguir desempeñando dos puestos de trabajo públicos en régimen de prestación a tiempo parcial. Ello provoca a su vez la modificación del plazo establecido legalmente para solicitar, en su caso, la autorización de compatibilidad, desde aquella fecha al 31 de diciembre siguiente. Hay, pues, un desajuste de los factores temporales manejados en la disposición reglamentaria catalana respecto de aquellos - ya expuestos - configurados en la norma legal correspondiente, desajuste en el desarrollo que lo invalida constitucionalmente» (f.j. 5).

«Un nuevo problema de Derecho intertemporal plantea la denuncia del art. 10 del Decreto 307/1985 por su contradicción con la cuarta de las Disposiciones 
RESEÑA DE SENTENCIAS DEL TRIBUNAL CONSTTUUCIONAL ..

transitorias de la Ley estatal sobre la materia. En ésta se exime -provisionalmente- de obtener autorización al profesorado universitario de Medicina, Farmacia y Enfermería para compatibilizar la actividad docente y la asistencial en los centros hospitalarios de la Universidad o concertados con la misma, pudiendo desarrollar ambas, conjuntamente, en régimen de dedicación completa o a tiempo parcial. No es dudoso, a nuestro parecer, el carácter básico de esta regulación sin que hayamos de repetir lo dicho más arriba sobre el factor temporal, ingrediente de cualquier norma. Teniendo tal carácter la configuración sustantiva de las situaciones de compatibilidad o incompatibilidad, esa cualidad se extiende necesariamente a sus efectos en el tiempo, al cuándo, para engarzar el sistema periclitado y el que se instaura. La exención transitoria de las autorizaciones pertinentes para desempeñar dos puestos de trabajo ha de recibir, pues, la misma calificación que la regla general cuya excepción constituye.

Pues bien, el art. 10 del Decreto catalán va más lejos, aun cuando empiece con una invocación a la regla transitoria sobredicha y ya en su encabezamiento, desde una perspectiva funcional, hable de "actividades docentes lectiva y complementaria asistencial en el ámbito universitario" concluye sin embargo que ambas son emanación de "un solo puesto de trabajo en la esfera docente". En realidad se trata de "plazas vinculadas", según la terminología que utiliza el Real Decreto 1558/1986. Está claro, pues, que su unión desborda el alcance temporal de la norma para hacerse permanente y configurar un nuevo supuesto de compatibilidad que, por ello mismo, no necesita autorización ahora ni la necesitará en el futuro, convirtiendo lo excepcional en normal. Esta unificación que opera la disposición reglamentaria es contraria, en los dos aspectos indicados, a la Ley básica, cuya finalidad defrauda, dejando abierta la posibilidad de que se produzcan efectos perturbadores en el sistema de incompatibilidades. En definitiva, una vez dicho esto, es clara la invalidez del precepto en cuestión» (f.j. 6).

Fallo: Estimar parcialmente este conflicto positivo de competencia y, en su virtud:

1. Declarar contrarios al orden constitucional de competencias los apartados segundo y tercero del art. 4 del Decreto del Consejo de Gobierno de la Generalidad de Cataluña 307/1985, en cuanto omite una determinada condición básica de la norma estatal.

2. Declarar inconstitucionales y nulos: el art. 8, en su apartado 2; el inciso «a partir de la entrada en vigor del presente Decreto» del art. 9, apartado primero; y el art. 10, todos ellos del mencionado Decreto.

3. Desestimar el conflicto en todo lo demás. 
REALA 273 (ENERO-ABRIL, 1997)

(Sentencia n. ${ }^{\circ}$ 172/1996, de 31 de octubre. Pleno. BOE 3 de diciembre de 1996. R. de Mendizábal Allende. Voto particular formulado por R. de Mendizábal Allende).

\section{CONFLICTOS DE COMPETENCIAS ENTRE COMUNIDADES AUTÓNOMAS}

1. Conflicto positivo de competencia núm. $96 / 1990$, planteado por el Gobierno de Castilla y León frente al Acuerdo del Consejo de Gobierno de la Diputación Regional de Cantabria, de 23 de agosto de 1989, que acordaba remitir a la Junta de Castilla y León ejemplar del proyecto de construcción y documentación complementaria de la obra de nueva carretera de Reinosa a Potes, tramo Brañavieja-Piedrasluengas; hacerse cargo la Diputación Regional de Cantabria de todos los costes referentes a la expropiación de bienes y terrenos, así como al cambio de servicios afectados que se produzcan en el tramo situado en la colindante Comunidad Autónoma; y delegar en el Consejero de Obras Públicas, Vivienda y Urbanismo la representación de la Diputación Regional de Cantabria en la firma de los Acuerdos que se establezcan con la Consejería de Fomento de la Junta de Castilla y León para llevar a efecto la mencionada actuación expropiatoria. El Tribunal declara que dicho Acuerdo, así como los actos de los que trae causa y los subsiguientes dimanantes de dicho Acuerdo, han vulnerado el orden constitucional y estatutario de competencias al quedar constatado que la actuación pretendida por la Comunidad Autónoma de Cantabria -la construcción de una carretera cuyo trazado discurre en parte por el territorio de Castilla y León-, ha excedido los límites territoriales que enmarcan el lícito ejercicio de sus competencias.

«El territorio, y de ahí su funcionalidad general en el entramado de distribución de competencias operada por la Constitución, los Estatutos de Autonomía y demás leyes integradas en el bloque de la constitucionalidad, se configura como elemento delimitador de las competencias de los poderes públicos territoriales (así, significativamente art. 32.1 del Estatuto de Cantabria), y, en concreto, como delimitador de las competencias de las Comunidades Autónomas en su relación con las demás Comunidades y con el Estado (STC 99/1986). Funcionalidad que, reconocida expresamente en los propios Estatutos, dimana de "la necesidad de hacer compatible el ejercicio simultáneo de las competencias asumidas por las distintas Comunidades" (STC 44/1984, fundamento jurídico 2. ${ }^{\circ}$ ), y que sirve directamente, en ocasiones como la presente, al objetivo de atribuir, localizándola en atención al ámbito en que se desarrollan las opor- 
RESEÑA DE SENTENCIAS DE TRIBUNAL CONSTTUCIONAL..

tunas actividades materiales (arts. 148.1.4 y 149.1.24 CE) la titularidad de la correspondiente competencia (ferrocarriles y carreteras, art. 148.1.5 CE, aprovechamientos hidráulicos e instalaciones eléctricas, art. 149.1.22), como de modo indubitado ha reconocido con carácter general la jurisprudencia de este Tribunal (STC 86/1988) y, específicamente, en relación con las actividades de transporte (SSTC 97/1983, 180/1992 y 118/1996).

Doctrina que, sin el menor asomo de duda, es de obligada extensión, en consonancia con el tenor literal de los preceptos constitucionales y estatutarios, al supuesto de las redes viarias de transporte (ferrocarriles y carreteras), cuya atribución competencial viene delineada por la concurrencia de dos criterios, el territorio y el interés, que, eventualmente, pueden yuxtaponerse, aun cuando, igualmente, puedan operar de modo autónomo o no convergente. De ahí que en supuestos como el aquí considerado, adquiera plena virtualidad la exigencia, consagrada en el art. 63.2 LOTC, de comunicar cuando de un conflicto entre Comunidades Autónomas se trate, el requerimiento de incompetencia al Gobierno de la Nación, a fin de que éste, como expresara el ATC 55/1981, pueda conocer "oficialmente de la iniciación del conflicto y pueda tomar, si lo estima por conveniente, las medidas a su alcance para intervenir en él" (fundamento jurídico $2^{\circ}$ ).

Pues bien, constatado que la actuación pretendida por la Comunidad Autónoma de Cantabria, la construcción de una carretera cuyo trazado discurre en parte por el territorio de la de Castilla y León, ha excedido los límites territoriales que enmarcan el lícito ejercicio de sus competencias, y habida cuenta que ningún dato permite un pronunciamiento acerca del eventual interés general de la obra proyectada, dimanante, en su caso, de la integración de la carretera en cuestión en la red viaria del Estado, dada la no comparecencia en el proceso del Gobierno de la Nación, la conclusión de cuanto antecede parece nítida: la Diputación Regional de Cantabria ha lesionado el ámbito competencial de la de Castilla y León, en la medida en que del proyecto cuestionado (siquiera, a efectos del presente conflicto, su exteriorización y concreción se produzca por el Acuerdo aquí cuestionado), puede afirmarse que viene afectado de un vicio de incompetencia, que se ha traducido, desde la perspectiva inherente al juicio que canalizan los procesos conflictuales, en una indebida invasión del ámbito competencial de la Comunidad Autónoma.

Tal vulneración del orden constitucional y estatutario de competencias pudiera ciertamente haberse evitado mediante la concertación de los oportunos Acuerdos o Convenios entre las dos Comunidades Autónomas (arts. 145.2 CE y 30 del Estatuto de Cantabria), que hubieran vertebrado el necesario principio de cooperación que se halla presente en la sustancia del Estado Autonómico, como reiteradamente ha proclamado este Tribunal (STC 146/1992). Acuerdos 
que, en rigor, debieran haber precedido a cualquier actuación unilateral con incidencia en la esfera competencial de otra entidad regional, modulando las exigencias del principio de territorialidad y flexibilizando el rigor excluyente que es inmanente a éste, como en distintas ocasiones ha señalado este Tribunal (SSTC, entre otras, 72/1983, 44/1984, 96/1984, 125/1984, 114/1985, 87/1987 y 103/1988), aunque siempre con el límite inexcusable de la necesaria concurrencia de la voluntad del ente cuyas competencias puedan verse afectadas por mor de la iniciativa suscitada (STC 53/1988; igualmente, de modo significativo, STC 101/1995 resolutoria de un conflicto promovido por Cantabria en relación con determinadas actuaciones del Gobierno del País Vasco en el municipio cántabro de Villaverde de Trucios).

Sin embargo, ello no ha sido así en el presente caso y ha conducido, según lo expuesto, a la lesión por la Comunidad de Cantabria de las competencias en materia de obras públicas y, más en concreto, de carreteras, de la Junta de Castilla y León. Sin que alcancen fuerza enervante de la constatada invasión competencial los contactos o reuniones habidos entre representantes de ambas Comunidades Autónomas en orden a la conclusión de los oportunos Acuerdos o Convenios de colaboración, cuya no formalización vicia de incompetencia las actuaciones seguidas y los Acuerdos adoptados por la Comunidad de Cantabria, que no cabe entender, según pretende su representación procesal, que fueron tácitamente consentidos por la de Castilla y León» (vid. f.j. 4).

«No se opone a la anterior consecuencia la eventual objeción acerca de la no efectividad, en sus vertientes de actualidad e inmediatez, de la invasión competencial denunciada, y que este Tribunal ha caracterizado como exigencia necesaria de la lesión amparable en vía conflictual (SSTC 116/1984, 137/1989 y 180/1992). En efecto, no puede afirmarse, según resulta de la descripción que antecede sobre el iter en que se concreta aquella invasión competencial, que el proyecto de construcción de la carretera, aun cuando ninguna traducción externa o material haya tenido (fuera de la mera aprobación unilateral del proyecto y la propia adjudicación de las obras), ha sido utilizado, en cuanto objeto de este proceso, como mero punto de partida para contrarrestar simples sospechas de actuaciones viciadas de incompetencia. $Y$ este es el caso de las tendentes a hacer efectiva la realidad de la carretera, como las de índole expropiatoria, supuesta la radical ausencia de potestades ablatorias de los derechos e intereses eventualmente afectados (STC 166/1987). Ni tampoco que la formalización del conflicto sólo se enderece a prevenir, con carácter cautelar, virtuales o hipotéticas lesiones, aún no producidas (STC 102/1988) sobre la base de suposiciones, conjeturas o juicios hipotéticos del promotor del conflicto, si bien, en todo caso, con base en un inequívoco fundamento (SSTC 67/1983, 95/1984, 88/1987, $53 / 1988$ y $249 / 1988)$. 
RESEÑA DE SENTENCLAS DE TRIBUNAL COASTTUUCIONAL...

Por el contrario, la mera aprobación del proyecto de construcción de la carretera, verdadero punctum saliens del debate competencial, ostenta virtualidad bastante para erigirse en criterio de imputación del proceso conflictual, dada la inequívoca extralimitación competencial que ha rodeado su proceso de emanación, y, en última instancia, es suficiente a fin de concluir en la vulneración del orden de competencias constitucional y estatutariamente dispuesto» (f.j. 5).

Fallo: Declarar que el Acuerdo del Consejo de Gobierno de la Diputación Regional de Cantabria, de 23 de agosto de 1989, relativo a la construcción de la carretera C-628, Reinosa-Potes, así como los actos de los que trae causa y los subsiguientes dimanantes de dicho Acuerdo, han vulnerado el orden constitucional y estatutario de competencias.

(Sentencia n. ${ }^{\circ}$ 132/1996, de 22 de julio. Pleno. BOE 12 de agosto de 1996. J. D. González Campos).

\section{JURISDICCIÓN CONTENCIOSO-ADMINISTRATIVA}

1. Recurso de amparo núm. 3361/1994 interpuesto contra la Sentencia de 22 de septiembre de 1994 y el Auto de aclaración de 27 de septiembre de 1994 de la Sección Segunda de la Sala de lo Contencioso-Administrativo del Tribunal Superior de Justicia de la Comunidad Valenciana, resoluciones recaídas en el proceso núm. 1389/1992, que desestiman pretensiones de la recurrente en amparo contra resolución de la Administración de la Generalidad Valenciana por la que se le eliminó del proceso de selección de concurso-oposición para cubrir determinadas plazas funcionariales. La cuestión estriba en determinar si la argumentación incorporada al fundamento de Derecho tercero de la sentencia impugnada, debidamente integrado, a su vez, con la rectificación que resulta del Auto de aclaración, ha vulnerado, en cuanto soporte del oportuno fallo desestimatorio, el derecho de tutela judicial efectiva consagrado en el art. 24.1 CE. El TC otorga el amparo.

«Es la incoherencia o quiebra del discurso lógico, contraída a la manifiesta discordancia entre el presupuesto argumental de la Sentencia recurrida y el resultado por ésta alcanzado, y que en última instancia se traduce en la carencia o insuficiencia de la motivación exigible (STC 32/1996, que cifra, justamente, con remisión a la STC 153/1995, en la falta de motivación necesaria para expresar "los criterios jurídicos esenciales fundamentadores de la decisión" - fundamento jurídico $50^{\circ}$ - la ratio del amparo otorgado en la ocasión), la causa de la estimación del presente recurso de amparo, cuyo otorgamiento, por vulnera- 
ción del art. 24.1 CE, conlleva la anulación de aquélla en el concreto extremo debatido y, por ende, la retroacción de actuaciones a fin de que por la Sala sentenciadora se dicte nuevo pronunciamiento, en el que, fijándose la puntuación mínima requerida, de conformidad con la correspondiente base de la convocatoria, para superar el primer ejercicio del procedimiento selectivo de que trae causa el proceso a quo, se declare si en la interesada concurría o no el derecho de acceder al segundo ejercicio del indicado procedimiento» (vid. f.j. 4).

Fallo: Estimar el presente recurso de amparo y en su virtud:

1. Reconocer a la recurrente en la integridad de su derecho a la tutela judicial efectiva.

2. Restablecerle en su derecho, para lo cual declaramos la nulidad de la Sentencia de 22 de septiembre de 1994 y del Auto de aclaración de 27 de septiembre de 1994 de la Sección Segunda de la Sala de lo Contencioso-Administrativo del Tribunal Superior de Justicia de la Comunidad Valenciana, recaídos en el proceso núm. 1389/1992, en el concreto extremo a que se refiere el fundamento de Derecho tercero de aquélla.

3. Ordenar la retroacción de actuaciones a fin de que por la Sala se dicte nuevo pronunciamiento, en el que se fije con precisión la puntuación mínima requerida para superar el primer ejercicio del procedimiento de selección de que trae causa el proceso judicial, y se declare si en la interesada concurría o no el derecho de acceder al segundo ejercicio del referido procedimiento.

(Sentencia n. ${ }^{\circ} 117 / 1996$, de 25 de junio. Sala Primera. BOE 29 de julio de 1996. V. Gimeno Sendra).

2. Recurso de amparo núm. $992 / 1994$, interpuesto contra la Sentencia de 26 de enero de 1994, de la Sección Séptima de la Sala de lo Contencioso-Administrativo del Tribunal Superior de Justicia de Madrid, recaida en el recurso contencioso-administrativo núm. 839/1991, sobre reclamación de funcionarios del Estado transferidos a la Comunidad Autónoma de Madrid por diferencias retributivas y equiparación económica. Los demandantes de amparo alegan la violación del derecho fundamental a utilizar los medios de prueba pertinentes para su defensa, por no haber tenido lugar la práctica de la prueba propuesta y admitida de la que dependería el éxito de su pretensión. El TC otorga el amparo.

«En el presente caso, admitida la prueba propuesta por los actores, acordada e incluso reiterada a la Administración demandada la petición de la certifi- 
RESEÑA DE SENTENCIAS DEL TRIBUNAL CONSTITUCIONAL ..

cación en que consistía, es preciso afirmar, en primer lugar, que del examen de las actuaciones no se desprende que la falta de su práctica fuera imputable a aquéllos. Por otra parte, ausente una motivación judicial, tampoco puede negarse de plano la pertinencia y la relevancia de la prueba propuesta, antes bien ha de presumirse su pertinencia y necesidad. Pero, de la lectura de la sentencia impugnada se desprende con toda claridad que la resolución desestimatoria del recurso contencioso-administrativo descansa íntegramente y como único motivo, en la imposibilidad para el órgano judicial de realizar el juicio de igualdad interesado por los recurrentes por no obrar en Autos ni en el expediente administrativo previo la documentación necesaria para ello y así en la sentencia expresamente se afirma. Más aún, el órgano judicial implícitamente llega a admitir que si tal documentación - precisamente la solicitada mediante la prueba admitida y no practicada - constase en Autos, su decisión podría ser otra de signo distinto.

Esos elementos de prueba de los que la Sala dice carecer para emitir su juicio podían resultar justamente de la documentación interesada por los actores como prueba y que, tras ser expresamente admitida e incluso reiterada mediante distintos proveídos, no llegó a practicarse por el comportamiento omisivo de la Administración. De este modo, el órgano judicial en lugar de adoptar otras medidas ofrecidas por las normas procesales para lograr la inmediata práctica de la prueba o compeler a la Administración a la remisión de la documentación interesada, optó por dictar una sentencia en la que con toda claridad vino a reconocer que, a diferencia de otros casos similares, en el presente había de desestimar el recurso por no acreditarse aquellos aspectos a los que directamente hacía referencia la prueba admitida y no practicada.

Al dictar, pues, sentencia sin que aquella prueba, reconocida como necesaria, se aportase al Tribunal, ha vulnerado el derecho fundamental a la utilización de los medios de prueba pertinentes (art. $24.2 \mathrm{CE}$ ) y provocado la indefensión que proscribe el apartado 1 del propio artículo. Como antes se ha puesto de relieve, a los órganos jurisdiccionales corresponde apreciar, en cada caso, la pertinencia de la prueba propuesta y el cumplimiento de los requisitos legalmente establecidos para su práctica así como rechazar aquellas que resulten inútiles para la fundamentación de su decisión o que no se hayan propuesto de acuerdo con lo dispuesto en las leyes. Pero han de posibilitar la práctica de todas aquellas otras propuestas en tiempo y forma por una parte, admitidas y declaradas pertinentes por revelarse necesarias para fundar la pretensión de quien las propuso, tanto más si, al resolver, el Tribunal advierte que de su aportación depende una decisión distinta a la que debería dictarse a falta de ellas. De no actuar así se quiebra el principio de contradicción y la garantía de defensa que el art. $24 \mathrm{CE}$ eleva al rango de derecho fundamental» (f.j. 3). 
Fallo: Otorgar el amparo solicitado y, en consecuencia:

1. Reconocer que se ha vulnerado a los recurrentes su derecho a la tutela judicial efectiva sin indefensión y a utilizar los medios de prueba pertinentes para su defensa.

2. Restablecerles en la integridad de su derecho y anular la Sentencia de 26 de enero de 1994, de la Sección Séptima de la Sala de lo Contencioso-Administrativo del Tribunal Superior de Justicia de Madrid.

3. Reponer las actuaciones al trámite de práctica de la prueba acordada.

(Sentencia n..$^{\circ}$ 164/1996, de 28 de octubre. Sala Segunda. BOE 3 de diciembre de 1996. J. Gabaldón López).

3. Recurso de amparo núm. 3685/1994, por dilaciones indebidas de la Sala Tercera del Tribunal Supremo en la tramitación del recurso de apelación núm. 6763/1992 interpuesto por el Ayuntamiento de Tarragona frente a la Sentencia de 15 de enero de 1991 del Tribunal Superior de Cataluña, que vino a estimar parcialmente un recurso Contencioso-Administrativo formulado por la ahora demandante en amparo, funcionaria del Ayuntamiento de Tarragona, quedando anuladas asi diversas sanciones de suspensión que se le impusieron, sustituyéndolas por otras de apercibimiento. El TC entiende que ha existido vulneración del derecho fundamental a un proceso público sin dilaciones indebidas y otarga el amparo con reconocimiento de indemnizaciones.

«Alega la demandante de amparo haber sufrido una vulneración de sus derechos fundamentales a la tutela judicial efectiva y a un proceso sin dilaciones indebidas (art. $24 \mathrm{CE}$ ) como consecuencia del retraso imputable a la Sala Tercera del Tribunal Supremo, en la tramitación del recurso de apelación interpuesto por el Ayuntamiento de Tarragona frente a la Sentencia de 15 de enero de 1991 del Tribunal Superior de Justicia de Cataluña, que vino a estimar parcialmente un recurso contencioso-administrativo formulado por dicha demandante de amparo, quedando anuladas así diversas sanciones de suspensión que se le impusieron, sustituyéndolas por otras de apercibimiento. La vulneración de tales derechos fundamentales se hace derivar de que, habiéndose personado ante esa Sala Tercera el día 15 de mayo de 1992, hasta el 13 de abril de 1993 no se le requirió para que fijara un domicilio a los efectos de notificaciones, tras lo que, y hasta la interposición del presente recurso de amparo el día 17 de noviembre de 1994, no había tenido noticia alguna de la situación de su recurso, que se encontraba paralizado. Con ello se le habrían causado diversos per- 
RESEÑA DE SENTENCIAS DEL TRIBUNAL CONSTTTUCIONAL ..

juicios, toda vez que, como consecuencia de la interposición del recurso de apelación, la sentencia de primera instancia, que revisó en sentido favorable a sus pretensiones las sanciones que se le impusieron, quedó suspendida.

El Ministerio Fiscal, por su parte, entiende que se han producido dilaciones indebidas por la tardanza excesiva en la tramitación del recurso, interesando que se conceda el amparo. Finalmente, el Ayuntamiento de Tarragona alegó que se había llegado a un acuerdo con la demandante en orden a la ejecución de la sentencia recurrida, a consecuencia del cual el Ayuntamiento desistió del recurso de apelación y ordenó el abono de las cantidades debidas, desistimiento que se ha admitido por el Tribunal Supremo por Auto de 26 de octubre de 1996. A consecuencia de ello, solicita que se declare la improcedencia del recurso de amparo habida cuenta de su falta de contenido» (f.j. 1).

«De otra parte, no puede aceptarse que la conclusión del recurso de apelación con posterioridad a la interposición de la demanda de amparo suponga una pérdida sobrevenida del objeto de este proceso constitucional, como entiende el Ayuntamiento de Tarragona e, incluso, la conducta procesal de la demandante podría inducir a considerar, al haberse desentendido de este recurso de amparo, puesto de manifiesto en el dato de que no ha formulado las alegaciones previstas en el art. 52 LOTC. Pero de esta omisión no puede extraerse consecuencia negativa alguna para la demandante más allá de lo que supone la propia pérdida del trámite. Debe, pues, resolverse acerca de si, al momento de la interposición del presente recurso se estaba vulnerando el derecho fundamental en cuestión, toda vez que la resolución tardía sana la vulneración del derecho a la tutela judicial efectiva pero no el del proceso sin dilaciones (SSTC $26 / 1983,5 / 1985$ y 35/1994)» (f.j. 3).

«El plazo de inactividad procesal transcurrido no está justificado, siendo, en consecuencia, no razonable (STC 144/1995), por lo que debe apreciarse y declararse que en la tramitación del recurso de apelación de referencia se produjo un supuesto de vulneración del derecho fundamental a un proceso sin dilaciones indebidas (art. 24.2 CE). Ahora bien, no siendo posible la restitutio in integrum del derecho fundamental dado que el proceso ha fenecido, el restablecimiento, solicitado por la recurrente, en la integridad de su derecho con la adopción de las medidas apropiadas, en su caso, para su conservación [art. 55.1, c) LOTC] sólo podrá venir por la vía indemnizatoria» (f.j. 8).

Fallo: Estimar el presente recurso de amparo y, en consecuencia:

1. Declarar que el derecho fundamental de la recurrente a un proceso sin dilaciones indebidas ha sido vulnerado en la tramitación realizada por la Sala Tercera del Tribunal Supremo del recurso de apelación de referencia. 
2. Restablecer a la recurrente en la integridad de su derecho mediante la correspondiente indemnización, en su caso, a cargo del Estado.

(Sentencia n. ${ }^{\circ}$ 180/1996, de 12 de noviembre. Sala Primera. BOE 17 de diciembre de 1996. P. Cruz Villalón).

\section{RECURSO DE AMPARO. CAUSAS DE INADMISIÓN}

1. Recurso de amparo núm. 2768/1994, promovido por el Ayuntamiento de Puertollano contra Sentencia de 5 de julio de 1994 de la Sala de lo Contencioso-Administrativo del Tribunal Superior de Justicia de Castilla-La Mancha, de 5 de julio de 1994, que estimando recurso contencioso-administrativo, declaró nula la resolución de la Comisión de Gobierno del Ayuntamiento de Puertollano por la que se excluyó de nombramiento de Policía Local en prácticas al actor del contencioso, y le impuso el deber de su nombramiento como Guardia de la Policía Local en prácticas. El Ayuntamiento de Puertollano, recurrente en amparo, entiende que se ha producido una vulneración del derecho fundamental a obtener la tutela efectiva de Jueces y Tribunales, pues imputa a la sentencia que es irrazonable y que quiebra el principio de legalidad en la medida que es condenado a nombrar al recurrente Guardia en prácticas, a pesar de haber aplicado la legalidad vigente. El TC inadmite el amparo solicitado en base a que el Ayuntamiento de Puertollano carece de legitimación para interponer el recurso de amparo.

«Entrando, pues, a examinar la presunta vulneración del derecho a la tutela judicial efectiva (art. 24.1 CE), hemos de abordar, en primer término, la cuestión de si el Ayuntamiento recurrente está legitimado para venir en amparo reclamando frente a su posible vulneración o, desde una perspectiva diferente, pero complementaria, la de si el recurso de amparo representa un cauce adecuado para solventar pretensiones como la que aquí se plantea.

En la STC 64/1988, en el marco de un análisis general de la "capacidad de derechos fundamentales", afirmamos que "por lo que se refiere al derecho establecido en el art. 24.1 de la Constitución, como derecho a la prestación de actividad jurisdiccional de los órganos del Poder Judicial del Estado, ha de considerarse que tal derecho corresponde a las personas físicas y a las personas jurídicas, y entre estas últimas, tanto a las de Derecho privado como a las de Derecho público, en la medida en que la prestación de la tutela efectiva de los Jueces y Tribunales tiene por objeto los derechos e intereses legítimos que les corresponden. $\mathrm{Y}$ así ha sido establecido por una extensa doctrina jurispruden- 
RESEÑA DE SENTENCIAS DE TRIBUNAL CONSTITUCIONAL ..

cial de este Tribunal, que no es necesario examinar aquí con detalle. Sin embargo, por lo que concierne a este último derecho, este Tribunal ha dicho que no se puede efectuar una íntegra traslación a las personas jurídicas de Derecho público de las doctrinas jurisprudenciales elaboradas en desarrollo del citado derecho fundamental en contemplación directa de derechos fundamentales de los ciudadanos. Por ello, hay que entender que, en línea de principio, la titularidad del derecho que establece el art. 24 de la Constitución corresponde a todas las personas físicas y a las personas jurídicas a quienes el ordenamiento reconoce capacidad para ser parte en un proceso y sujeta a la potestad jurisdiccional de Jueces y Tribunales, si bien en este último caso el reconocimiento del derecho fundamental debe entenderse dirigido a reclamar del órgano jurisdiccional la prestación a que como parte procesal se tenga derecho."

Ulteriormente en la STC 197/1988, tras reiterar dicha doctrina, precisamos que cuando "los órganos públicos no actúan como decisores de conflictos de intereses, ni ostentan un interés propio que se oponga al de otro ente público implicado en la decisión, sino que ejercen funciones de control de la legalidad", "la decisión de estos órganos públicos, garantes de la legalidad de los actos de otros órganos igualmente públicos, no compromete, ni incide en el interés legítimo de estos últimos", por lo que la falta de un recurso jurisdiccional no menoscaba, en tales supuestos, el derecho a la tutela judicial.

Esta línea jurisprudencial, relativa al derecho de acceso a la jurisdiccion, ha sido reafirmada y profundizada recientemente en la STC 129/1995, al negar que la Administración General del Estado pueda hacer valer el art. 24.1 CE para comparecer ante los Juzgados de Vigilancia Penitenciaria en defensa de los actos de los Centros Penitenciarios» (f.j. 3).

«Si, cuando de entes públicos se trata, el art. 24.1 de la Constitución, en su vertiente de derecho de acceso a la jurisdicción, no puede aplicarse sin las modulaciones a que acaba de hacerse referencia, es obvio que otro tanto cabrá decir si se examina su contenido desde la perspectiva del derecho a una resolución de fondo.

En efecto, en la STC 257/1988 denegamos el amparo pretendido por una Diputación Foral y fundado en la presunta vulneración del art. 14 de la Constitución, precisando que la legitimación para interponer el recurso de amparo requiere que "quien aparezca como demandante se halle en una específica relación con el objeto de las pretensiones que pueden deducirse en esta vía, ya consista tal relación en la titularidad propia de un derecho o libertad fundamental presuntamente vulnerado o, incluso, en un mero interés legítimo en la preservación de derechos o libertades, igualmente fundamentales, de otros". Señalamos entonces que el recurso de amparo "no constituye una vía abierta a los poderes 
públicos para la defensa de sus actos y de las potestades en que éstos se basan, sino, justamente, un instrumento para la correcta limitación de tales potestades y para la eventual depuración de aquellos actos, en defensa de los derechos fundamentales y libertades públicas de los particulares".

Pues bien: el examen de la demanda y alegaciones efectuadas por el Ayuntamiento recurrente pone de manifiesto que lo que se impugna es, meramente, la interpretación de la legalidad efectuada por el Tribunal Superior de Justicia de Castilla-La Mancha en defensa del acto del Ayuntamiento anulada por su sentencia.

Por ello es preciso concluir, por tanto, que el Ayuntamiento de Puertollano carece de legitimación para interponer el recurso de amparo (STC 257/1988)» (f.j. 4).

Fallo: Inadmitir el amparo solicitado por el Excelentísimo Ayuntamiento de Puertollano.

(Sentencia n. $^{\circ}$ 123/1996, de 8 de julio. Sala Segunda. BOE 12 de agosto de 1996. T. S. Vives Antón).

\section{ACTIVIDAD ADMINISTRATIVA SANCIONADORA}

1. Recurso de amparo núm. 3205/1993 contra la Resolución de 26 de mayo de 1992 de la Alcaldia de Fuengirola sancionadora por dos faltas de grave desconsideración con los superiores y por una falta leve de incumplimiento de las normas de uniformidad, cometidas por un Agente de la Policía Local, y contra la Sentencia de 15 de julio de 1993 de la Sala de lo Contencioso-Administrativo del Tribunal Superior de Justicia de Andalucía que desestima el recurso interpuesto por la vía de la Ley 62/1978, de 26 de diciembre de Protección de Derechos Fundamentales. El recurrente en amparo imputa al procedimiento administrativo sancionador no aplicar las garantías del artículo 24.2 de la CE; resolverse el expediente con anterioridad a la terminación de la instrucción; ser sancionado por las manifestaciones críticas hechas en el ejercicio de su derecho de defensa y, finalmente, falta de tipificación de los hechos sancionados en la norma aplicable. El TC otorga el amparo por entender que ha existido vulneración de los derechos fundamentales a obtener la tutela efectiva de Jueces y Tribunales y a la libertad de expresión y del principio de legalidad penal.

«Las vulneraciones - lesivas del art. 24.2 CE- que se atribuyen ahora al procedimiento sancionador fueron tempestiva y adecuadamente expuestas ante 
la Sala de lo Contencioso-Administrativo del Tribunal Superior de Justicia de Andalucía: falta de claridad de los hechos imputados en el primer Decreto de apertura del expediente disciplinario; denegación de la vista íntegra del expediente; denegación fáctica e inmotivada de las pruebas solicitadas; resolución sancionadora previa a la finalización de la instrucción y a la propuesta del instructor. La respuesta que obtuvo el recurrente figura en el fundamento $7 .^{\circ} \mathrm{de}$ la Sentencia: "por lo que se refiere al art. 24.2, que también se alega violado po los actos recurridos, basta la simple lectura del mismo, referido en todo momento a la actuación judicial, para ver que en ningún caso se puede violar por un procedimiento administrativo sancionador".

Debe afirmarse, sin ningún margen de dudas, que la respuesta judicial transcrita al no aplicar las garantías del art. 24.2 CE resulta manifiestamente irrazonable y, con ello, lesiva, como pretende el recurrente, de su derecho a la tutela judicial efectiva. En efecto, constituye una inveterada doctrina jurisprudencial de este Tribunal y, ya, postulado básico de la actividad sancionadora de la Administración en el Estado social y democrático de Derecho, el que, con las lógicas adaptaciones y modulaciones, "los principios esenciales reflejados en el art. 24 de la CE en materia de procedimiento han de ser aplicables a la actividad sancionadora de la Administración en la medida necesaria para preservar los valores esenciales que se encuentran en la base del precepto y la seguridad jurídica que garantiza el art. 9 de la CE" (STC 18/1981, fundamento jurídico $\left.2^{\circ}\right)^{\circ} \gg($ vid. f.j. 5).

«Resulta sorprendente el hecho de que la fecha que figura en la resolución de sanción sea anterior a la finalización de la instrucción y, con ello, a la de la propuesta del instructor y a la de diversos escritos de alegaciones y de aportación de pruebas al expediente ( 4 de junio y 25 de julio). Tamaña irregularidad no puede imputarse ahora a un error material, a la vista del radical silencio del Ayuntamiento en la vía judicial y en esta sede, y debe conducir a la estimación del amparo por vulneración del derecho a la defensa. El hecho de que se zanjara precipitadamente el expediente en fase aún de alegación y prueba ha generado una indefensión en el procedimiento administrativo de tal entidad que no es subsanable en el ulterior proceso judicial (STC 160/1994)» (vid. f.j. 7).

«El vicio más radical que se imputa a la sanción leve impuesta (dos días de suspensión de funciones) es el de legalidad. El comportamiento sancionado ("llevar el pelo más largo de lo correcto e incluso recogido habitualmente en forma de "coleta"') no quedaría comprendido en el precepto sancionador (art. 8.6, del Real Decreto 884/1989: (...) incumplimiento de las normas de uniformidad], que fue integrado por el órgano sancionador con un Decreto de la Alcaldía que sería nulo por la falta de competencia (...). 
En el presente supuesto estamos ante un problema formal de legalidad, pues, como afirma el Ministerio Fiscal, el comportamiento sancionado no estaba tipificado en la norma aplicada. Y no lo estaba porque la norma de cumplimiento a la que se remite la misma en relación con el concreto conflicto suscitado, y sin la que queda sin contornos mínimamente precisos, no reúne los requisitos imprescindibles de validez. Frente a lo que afirma el encabezamiento del Decreto discutido de la Alcaldía de Fuengirola sobre uniformidad y saludo de la Policía Local, que justifica la atribución al respecto de aquélla en el art. 21.1 h) de la Ley 7/1985, de 2 de abril, reguladora de las Bases del Régimen Local ("ejercer la Jefatura de la Policía Municipal, así como el nombramiento y sanción de los funcionarios que usen armas"), es el propio Tribunal Superior de Justicia de Andalucía (fundamento jurídico $8 .^{\circ}$ de la sentencia impugnada que, no obstante, por error, no ampara el motivo) el que sitúa la competencia al respecto entre las propias del Pleno del Ayuntamiento [art. $22.2 \mathrm{~d}$ ): "La aprobación del Reglamento orgánico y de las Ordenanzas"]. La Ley habilita al Pleno del Ayuntamiento y no a la Alcaldía.

La falta, pues, de una razonable subsunción de los hechos en el precepto aplicado, frente a la razonable exclusión que deriva de las propias afirmaciones del Tribunal Superior de Justicia de Andalucía, del informe del Ministerio Fiscal y del informe técnico que aporta el recurrente de la Dirección General de Política Interior de la Junta de Andalucía, conducen a la estimación del motivo. Con ella, y con la anulación de la parte correspondiente de la resolución y de la Sentencia recurridas decae, el objeto de los motivos que la impugnaban por razones de igualdad y del derecho a la propia imagen» (vid. f.j. 8).

"Cuando la defensa verbal lo sea de los propios argumentos y el ataque se dirija a la fundamentación y racionalidad jurídica del acto administrativo o de sus efectos, "para nada comprometen el respeto debido al órgano autor de aquél cuando es manifiesta su directa conexión con estrictos argumentos de legalidad, porque, por imperativo constitucional (art. $103 \mathrm{CE}$ ) el propio órgano que dictó el acto se halla también directa e inexcusablemente implicado en el cumplimiento de la ley" (fundamento jurídico $3 .^{\circ}$ ).

En el presente supuesto debemos convenir, con el Ministerio Fiscal, que los órganos administrativo y judicial no realizaron una ponderación adecuada de los intereses en juego, con lesión de la libertad de expresión en relación con el derecho de defensa. Esta conclusión es el corolario de dos constataciones. La primera, que, a pesar del vehículo atípico utilizado - los partes de servicio-, pero en todo caso interno, las manifestaciones sancionadas constituyeron, como señala el Fiscal, un acuse de recibo y la expresión inicial de unas alegaciones defensivas. El segundo dato crucial que conduce al amparo es que los calificativos discutidos no se refieren a personas, sino al Decreto que inicia el 
RESEÑA DE SENTENCLAS DEL TRIBUNAL CONSTTTUCIONAL..

expediente ("absurdo") y a los hechos que se le imputan ("falsos" y "tendenciosos"), y son coherentes con la estrategia de argumentación jurídica que posteriormente siguió el expedientado» (vid. f.j. 10).

Fallo: Estimar el recurso de amparo, y en su virtud:

1. Declarar que la Sentencia de la Sala de lo Contencioso-Administrativo del Tribunal Superior de Justicia de Andalucía, 584/1993, de 15 de julio, ha vulnerado el derecho del recurrente a la tutela judicial efectiva (art. 24.1 CE) en lo que respecta al motivo que invocaba la infracción del art. 24.2 CE.

2. Declarar que en el expediente disciplinario que finalizó con la Resolución de la Alcaldía de Fuengirola de 26 de mayo de 1992 se ha vulnerado el derecho a la defensa del recurrente (art. 24.2 CE).

3. Declarar que la citada Resolución, respecto a la falta leve, ha vulnerado los derechos del recurrente a no ser sancionado por acciones que en el momento de producirse no constituyan infracción administrativa según la legislación vigente en aquel momento (art. 25.1 CE) y, respecto a las dos faltas graves, la libertad de expresión en relación con el derecho de defensa [arts. 20.1 a) y 24.2 CE].

4. Anular la Resolución y la Sentencia citadas en este fallo.

(Sentencia n. ${ }^{\circ}$ 120/1996, de 8 de julio. Sala Segunda. BOE 12 de agosto de 1996. C. Viver Pi-Sunyer).

\section{AGUAS}

1. Recurso de inconstitucionalidad núm. 1367/1987 promovido por el Presidente del Gobierno contra diversos preceptos de la Ley del Parlamento de Cataluña 17/1987, de 13 de julio, reguladora de la Administración Hidráulica de Cataluña. El presente recurso atañe a tres preceptos especificos de la Ley que regula la Administración Hidráulica de Cataluña, en cuanto asigna a ésta diversas potestades de ordenación y sanción sobre aprovechamientos que corresponden a cuencas hidrográficas que excedan del ámbito de una Comunidad Autónoma, en detrimento de las atribuciones de las correspondientes Confederaciones Hidrográficas de competencia estatal. El TC estima el recurso y declara inconstitucionales los arts. 35.2 y 38, apartados 1 y 2, de la mencionada Ley.

«Es indudable que al Estado corresponde la legislación, la ordenación y la concesión de recursos y aprovechamientos hidráulicos en las cuencas hidrográ- 
ficas que superan el territorio de Cataluña. Por lo que la Ley que regula su Administración Hidráulica no puede contradecir lo dispuesto por la Ley de Aguas sobre los organismos encargados de gestionar las cuencas de competencia estatal, so pena de vulnerar el orden constitucional de competencias y, por ende, incurrir en invalidez.

Esto no significa, como afirman las partes personadas en defensa de la Ley recurrida, que la Ley estatal defina o delimite las competencias asumidas por la Comunidad Autónoma mediante su Estatuto. Significa, simplemente, que el ejercicio de sus competencias por parte de las instituciones centrales del Estado sobre las cuencas hidrográficas de su competencia condicionan la actuación que puede llevar a cabo la Comunidad Autónoma en dichas cuencas. El modo más directo que tiene la Comunidad Autónoma para incidir en los intereses afectados por la administración de las aguas en las cuencas que, como la del Ebro o la del río Garona, se extienden más allá de su territorio, es mediante su participación en los órganos de gobierno de las correspondientes Confederaciones Hidrográficas, en los términos previstos por la legislación estatal (art. 23 de la Ley de Aguas y Reales Decretos 931/1989 y 924/1989, ambos de 21 de julio, que rigen respectivamente las Confederaciones Hidrográficas del Ebro y del Júcar), respetando siempre el marco constitucional, que incluye como principio esencial el principio de colaboración entre el Estado y las Comunidades Autónomas, subrayado en la sentencia sobre la legislación estatal de Aguas [STC 227/1988, fundamento jurídico 20 , letras b) y e)] como eco de otros muchos pronunciamientos en ese sentido (SSTC 64/1982,fundamento jurídico $8 .^{\circ}$, $76 / 1983$, fundamento jurídico $11 ; 104 / 1988$, fundamento jurídico $5 .^{\circ}$, y $13 / 1992$ fundamento jurídico $7 .^{\circ}$ in fine). Las actuaciones que pueda llevar a cabo directamente cada una de las Administraciones autonómicas sobre las aguas de las cuencas hidrográficas que discurren por varias Comunidades Autónomas no son más que complemento de la que desarrollan participando en la dirección y gestión de la propia Confederación Hidrográfica, y sólo son factibles en la medida en que no interfiera la actuación de ésta ni la perturbe (STC 77/1984, fundamento jurídico $2 .^{\circ}$ ).

A partir de estos criterios podemos adentrarnos en el análisis de cada uno de los preceptos impugnados en este recurso de inconstitucionalidad» (f.j. 5).

«Las comunidades de usuarios, ya adopten la denominación de comunidades de regantes u otra distinta, en función del destino principal dado a las aguas por los usuarios que las forman son corporaciones de Derecho público cuya finalidad no es otra que la gestión autónoma de los bienes hidráulicos necesarios para los aprovechamientos colectivos de los usuarios de aguas públicas (arts. 73 y ss. de la Ley de Aguas, STC 227/1988, fundamento jurídico 24). 
RESEÑA DE SENTENCLAS DEL TRIBUNAL CONSTITUCIONAL ...

En la sentencia 227/1988 sobre la Ley de Aguas quedó claro que las normas estatales que regulan estas entidades son constitucionales incluida la dualidad de adscripciones establecida por las disposiciones legales, que las hacen depender ora de las Administraciones autonómicas, ora de los organismos de cuenca estatales. Las comunidades de usuarios que toman sus aguas de cuencas intracomunitarias están adscritas a la Administración hidráulica de la correspondiente Comunidad Autónoma, de acuerdo con su Estatuto y la disposición adicional cuarta de la Ley de Aguas. Por el contrario, las comunidades de usuarios cuyas concesiones recaen sobre aguas de cuencas intercomunitarias están adscritas al organismo de cuenca competente y sometidas a la legislación del Estado, tal y como dispone el núm. 22 del art. 149.1 CE (STC 227/1988, fundamento jurídico 24).

Por ende, las Comunidades Autónomas ejercen funciones normativas, así como ejecutivas, sobre las comunidades de usuarios adscritas a su Administración Hidráulica, pero no sobre las corporaciones de cuencas de competencia estatal. Estas últimas dependen del organismo de cuenca en todos los aspectos de su creación y actuación, tal y como detallan los arts. 73 y siguientes de la Ley de Aguas, cuya constitucionalidad fue respaldada en la tantas veces mencionada STC 227/1988» (f.j. 6).

«Ello implica que la competencia que el art. 35.2 de la Ley recurrida asigna a la Junta de Aguas de Cataluña, de cuidar del buen orden del aprovechamiento y ejercer las demás funciones que le otorgue el ordenamiento jurídico "en relación con las comunidades situadas en el resto del territorio de Cataluña", que son titulares de aprovechamientos pertenecientes a cuencas hidrográficas que excedan del ámbito de una Comunidad Autónoma, desborda las competencias propias de la Generalidad de Cataluña. Como indicamos en la STC 227/1988, en relación con la entidad entonces recurrente, "la Comunidad Autónoma del País Vasco dispone de un amplio margen de libertad de decisión para la configuración normativa de los organismos correspondientes que dependan de su propia Administración hidráulica" (STC 227/1988, fundamento jurídico 24.6); no, en cambio, para regular corporaciones de Derecho público que forman parte de la Administración estatal de las aguas, al gestionar concesiones de "aguas que (discurren) por más de una Comunidad Autónoma" art. 149.1.22 CE).

Cabe añadir, además, que la Ley de Cataluña (art. 35.2) otorga a la Junta de Aguas cuando se trata de aprovechamientos hidráulicos situados en Cataluña pero pertenecientes a una cuenca supracomunitaria funciones ya atribuidas al organismo estatal por el art. 74.1 de la Ley de Aguas a fin de velar por el cumplimiento de los Estatutos y Ordenanzas de dichas corporaciones de Derecho público y por el buen orden del aprovechamiento STC 227/1988, fundamento jurídico 24). 
La Administración Hidráulica de Cataluña puede ejercer funciones y potestades sobre las comunidades de usuarios que le están adscritas, por gestionar aguas de cuencas hidrográficas de competencia de la Generalidad. Pero las corporaciones de Derecho público que dependen de las Confederaciones Hidrográficas de ámbito supracomunitario quedan fuera de su círculo de competencia en materia de aguas. Por lo que el art. 35.2 de la Ley catalana 17/1987 es inconstitucional y nulo» (f.j. 7).

«A idéntica conclusión se llega respecto de las potestades de sanción y resarcimiento que el art. 38 de la Ley recurrida, en sus dos primeros apartados, asigna a la Administración Hidráulica de Cataluña, dejando relegado al organismo de cuenca a conocer de los eventuales recursos de alzada que los interesados pudieran interponer contra las resoluciones adoptadas por la Generalidad.

Al margen de lo anómalo que resulta, dentro de la relación entre el Estado y las Comunidades Autónomas, la configuración de un recurso administrativo que implica el sometimiento de la actuación de la Administración autonómica al control de legalidad por un organismo estatal, ha de señalarse que estas atribuciones perfectamente lícitas cuando recaen sobre infracciones cometidas en las cuencas comprendidas íntegramente dentro del territorio de Cataluña [art. 3.1 a) de la Ley de la Administración Hidráulica de Cataluña], dejan de serlo cuando recaen sobre conductas realizadas en cuencas hidrográficas cuyas aguas discurren más allá del territorio de la Comunidad Autónoma. Este criterio territorial es el establecido por la Constitución y el Estatuto de Autonomía de Cataluña para repartir las competencias en esta materia de aguas, y a él deben atenerse los legisladores que la regulen (STC 227/1988, fundamentos jurídicos 15 y 18).

Las infracciones que puedan cometerse en cuencas hidrográficas supracomunitarias están sometidas a la legislación del Estado. Tal y como declaramos en la STC 227/1988, fundamento jurídico 29, las Comunidades Autónomas con competencia en materia de aguas pueden establecer su propia legislación sancionadora en relación con los aprovechamientos hidráulicos de su competencia, incluida la policía demanial o de aguas. Competencia que, en el caso de la Comunidad Autónoma demandada, existe "cuando las aguas discurran íntegramente dentro de Cataluña" (art. 9.16 EAC).

Por consiguiente, como el art. 38.1 y 38.2 de la Ley recurrida otorgan competencias ejecutivas sobre aguas que forman parte de cuencas hidrográficas de competencia estatal, invaden la competencia exclusiva que el núm. 22 del art. 149.1 CE reserva al Estado sobre las aguas que discurren por más de una Comunidad Autónoma, como ya se declaró en el fundamento jurídico 29 de la STC 227/1988» (f.j. 8). 
RESEÑA DE SENTENCIAS DEL TRIBUNAL CONSTITUCIONAL ..

«Las conclusiones anteriores se refuerzan, por lo demás, atendiendo a otro orden de consideraciones. En la STC 227/1988 declaramos inconstitucional la letra c) del art. 16.1 de la Ley de Aguas, que creaba un Delegado del Gobierno en la Administración Hidráulica de las Comunidades Autónomas. La razón estribaba, precisamente, en que "la mera previsión legal de dicha figura organizativa conculca las competencias que las Comunidades Autónomas tienen para organizar libremente sus propias instituciones" [STC 227/1988, fundamento jurídico $21 \mathrm{c})$ ].

En sentido inverso, es claro que los preceptos impugnados no se ajustan al orden constitucional de competencias, en cuanto llevan a la Administración Hidráulica catalana a interferir la organización y atribuciones de las Confederaciones Hidrográficas establecidas por la Ley 29/1985 de Aguas. Lo cual es especialmente patente en lo relativo a la policía de las aguas, al transformar la potestad resolutoria de las Confederaciones sobre las infracciones leves y menos graves en la mera facultad de resolver recursos administrativos sobre las resoluciones adoptadas por la Administración autonómica» (f.j. 9).

Fallo: Declarar inconstitucionales y nulos los arts. 35, apartado 2, y 38, apartados 1 y 2, de la Ley 17/1987, de 13 de julio, reguladora de la Administración Hidráulica de Cataluña.

(Sentencia n. ${ }^{\circ} 161 / 1996$, de 17 de octubre. Pleno. BOE 5 de noviembre de 1996. A. Rodríguez Bereijo).

\section{DERECHO PÚBLICO DE LA ECONOMÍA}

\section{A) Presupuestos Generales}

1. Recurso de inconstitucionalidad núm. 1106/1988 promovido por el Gobierno de la Nación, representado por el Abogado del Estado contra el art. 10, apartados $4 .^{\circ}$ y $5 .^{\circ}$ y la disposición adicional decimocuarta de la Ley del Parlamento de Galicia 2/1988, de 5 de marzo, de Presupuestos Generales de la Comunidad Autónoma de Galicia para 1988. La creación por la Ley de Presupuestos de Galicia de un fondo para mejoras retributivas del personal al servicio de la Administración de Galicia, contraviene el tope máximo global fijado por el Estado en la Ley de Presupuestos Generales al incremento de la masa retributiva, vulnerando asi el principio de coordinación de la Hacienda de la Comunidad Autónoma con la Hacienda estatal y de la competencia del Estado sobre las bases y coordinación de la planificación general de la actividad económica. El Tribunal 
declara inconstitucionales los apartados $4 .^{\circ}$ y $50^{\circ}$ del art. 10 de la citada Ley, y desestima el recurso en todo lo demás.

«Se imputa, en primer término, a los apartados $4 .^{\circ}$ y $5 .^{\circ}$ del art. 10 de la Ley autonómica la quiebra del orden constitucional de competencias, toda vez que, al crear unos fondos para financiar mejoras adicionales con independencia del incremento retributivo del $4 \%$, contraviene claramente dicho tope máximo fijado para el personal al servicio de las diferentes Administraciones Públicas por el art. 28 de la Ley de Presupuestos Generales del Estado» (vid. f.j. 2).

«Procede ya determinar si la normativa autonómica impugnada contradice, en efecto, los reiterados límites retributivos establecidos en el citado art. 28 de la Ley 33/1987 de Presupuestos Generales del Estado en cuyo caso resultaría manifiesta su inconstitucionalidad por vulnerar el art. 149.1.13 CE y el límite a la autonomía financiera en que consiste el principio de coordinación (art. 156.1 $\mathrm{CE})$, según éste resulta perfilado por una norma integrante del bloque de la constitucionalidad cual es el art. 2.1 b) LOFCA (por todas, SSTC 181/1988, fundamento jurídico $7 .^{\circ} ; 183 / 1988$, fundamento jurídico $3 .^{\circ} ; 250 / 1988$, fundamento jurídico $1 .^{\circ}$; $150 / 1990$, fundamento jurídico $3^{\circ}$, y $68 / 1996$ fundamento jurídico $9 .^{\circ}$ ).

Ciertamente, ha de convenirse con el Abogado del Estado en que existe la denunciada contradicción entre los preceptos de la Ley presupuestaria estatal y los de la autonómica ahora impugnados. Verdad es que en los apartados 1., $2 .^{\circ}$ y $3 .^{\circ}$ del art. 10 de la Ley autonómica se recoge en términos análogos, y a veces idénticos el límite del $4 \%$ fijado en el art. 28 de la Ley estatal. Ahora bien, el establecimiento, en los recurridos apartados $4 .^{\circ}$ y $5 .^{\circ}$, de unos fondos adicionales para finalidades específicas -que, al superponerse al reiterado tope, vendrían a excederlo- incide, menoscabándola, en la eficacia de la medida antiinflacionaria adoptada por el Estado. Dicho sea todo ello con independencia de que, entre dichas finalidades, se encuentre alguna constitucionalmente legítima tal como la dirigida a la ejecución de resoluciones judiciales firmes prevista en el inciso final del apartado $5 .^{\circ}$ del art. 10 de la Ley impugnada y, por supuesto también, con independencia de las razones aducidas por el legislador autonómico para justificar la creación de dichos fondos complementarios. Por lo demás, no desvirtúa esta aseveración la alegación, sustentada en los escritos de oposición al recurso, según la cual atenta contra el principio de igualdad el hecho de que el Estado impugne ahora una práctica de la que había hecho uso en anteriores ejercicios económicos, toda vez que el límite de los incrementos retributivos contenido en la norma estatal, se extiende con idéntico alcance a la totalidad de las Administraciones Públicas. 
RESEÑA DE SENTENCLAS DEL TRIBUNAL CONSTITUCIONAL ..

En definitiva, en la medida en que los apartados $4 .^{\circ}$ y $5 .^{\circ}$ del art. 10 de la Ley del Parlamento de Galicia $2 / 1988$, de una parte, desconocen el límite que a su autonomía financiera impone el principio de coordinación art. 156.1 CE y 2.1 b) LOFCA y, de otro lado vulneran la competencial estatal ex art. 149.1.13 $\mathrm{CE}$, han de reputarse inconstitucionales, por lo que en este extremo debe estimarse el recurso que nos ocupa» (f.j. 4).

Fallo: Estimar parcialmente el recurso de inconstitucionalidad y, en su virtud:

1. Declarar la inconstitucionalidad y nulidad de los apartados $4 .^{\circ}$ y $5 .^{\circ} \mathrm{del}$ artículo 10 de la Ley $2 / 1988$, de 5 de marzo, de Presupuestos Generales de la Comunidad Autónoma de Galicia para el año 1988.

2. Desestimar el recurso en todo lo demás.

(Sentencia n. ${ }^{\circ}$ 171/1996, de 30 de octubre. Pleno. BOE 3 de diciembre de 1996. E. Ruiz Vadillo).

\section{B) Pesca}

1. Impugnación núm. 1504/1988 al amparo del Título V de la Ley Orgánica del Tribunal Constitucional que promueve el Gobierno de la Nación en relación con el Decreto 48/1988, de 28 de abril de la Comunidad Autónoma de las Islas Baleares por el que se regula la Pesca de arrastre de fondo de las Islas Baleares. El TC declara que la titularidad de la competencia controvertida corresponde al Estado, y, en consecuencia, la nulidad de la citada disposición.

«Un Decreto (el 48/1988 sobre Pesca de arrastre de fondo en las Islas Baleares), cuyo ámbito de aplicación no se circunscribe a las "aguas interiores" sino, con mayor extensión, a las aguas de las Islas Baleares, sin determinar su límite externo. Según se desprende de su art. 2 y del escrito de alegaciones del representante de la Comunidad Autónoma de las Islas Baleares es evidente, por tanto, que a su través la Comunidad Autónoma pretende ordenar normativamente una particular modalidad extractiva de pesca. Así se deduce no sólo de la rúbrica del Decreto impugnado sino también de todas y cada una de las disposiciones contenidas en su articulado (...).

Todo ello evidencia que nos encontramos ante la regulación por la Comunidad Autónoma de una modalidad de pesca (el arrastre de fondo) en aguas si- 
tuadas más allá de las aguas interiores, con determinación de todos los elementos imbricados en esa modalidad de pesca como actividad extractiva, lo que, según queda dicho, pertenece a la competencia exclusiva del Estado conforme a lo dispuesto en el art. 149.1.19.a de la Constitución. Siendo ello así, es claro que el Decreto impugnado no respeta el orden constitucional de distribución de competencias en la materia, invadiendo con su regulación un ámbito material que la Constitución reserva a la competencia exclusiva del Estado» (vid. f.j. 4).

Fallo: 1. Que corresponde al Estado la titularidad de la competencia ejercida en el Decreto 48/1988, de 28 de abril, de la Comunidad Autónoma de las Islas Baleares.

2. La nulidad de la citada disposición.

(Sentencia n. ${ }^{\circ}$ 184/1996, de 14 de noviembre. Pleno. BOE 17 de diciembre de 1996. T. S. Vives Antón).

\section{C) Energía}

1. Conflicto positivo de competencia núm. 1324/87, promovido por el Consejo Ejecutivo de la Generalidad de Cataluña, en relación con el Real Decreto 664/1987, de 15 de abril, por el que se declara de utilidad pública la ampliación de la red de oleoductos a instalar y explotar por la «Companía Arrendataria del Monopolio de Petróleos, Sociedad Anónima» (CAMPSA). La cuestión suscitada en el presente proceso constitucional se contrae a decidir la instancia territorial competente para autorizar y declarar de utilidad pública a efectos expropiatorios el oleoducto Tarragona-Barcelona-Girona, resolviendo sobre la adecuación al orden competencial del Real Decreto 664/1987 de 15 de abril, en cuanto en el mismo se incluye dicho oleoducto. El Tribunal declara que la competencia controvertida corresponde a la Comunidad Autónoma de Cataluña.

«Ambas representaciones coinciden en afirmar que el título competencial directa y suficientemente aplicable al caso es el recogido en el art. $9.16 \mathrm{del}$ EAC, que atribuye a la Generalidad competencia exclusiva sobre los preceptos que reserva al Estado la competencia exclusiva sobre las "... instalaciones de producción, distribución y transporte de energía, cuando este transporte no salga de su territorio y su aprovechamiento no afecte a otra Provincia o Comunidad Autónoma ..." (...). Con arreglo al mencionado art. 9.16 del EAC, y así lo entienden ambas partes, el Estado, sin perjuicio de la expresa previsión del art. 149.1.22 CE respecto a las instalaciones eléctri- 
cas, es competente, ex art. 149.3 CE, para autorizar cualquier instalación de transporte de energía cuando este transporte salga del ámbito territorial de la Comunidad Autónoma o su aprovechamiento afecte a otra Provincia o Comunidad Autónoma y, a sensu contrario, la Generalidad lo es cuando no se produzca ninguna de las dos condiciones reseñadas. De forma que, como tiene declarado este Tribunal Constitucional sobre el alcance de la competencia controvertida, basta con que en relación con cualquier instalación de transporte de energía se dé una de las dos condiciones enumeradas en negativo por el Estatuto de Autonomía para que la competencia de autorización sea estatal» (vid. f.j. 3).

«No existe desacuerdo entre las representaciones de una y otra parte respecto a que el oleoducto transcurra íntegramente dentro del ámbito territorial de la Comunidad Autónoma y no discuten, en consecuencia, sobre la primera de las dos condiciones enunciadas en negativo por el art. 9.16 del EAC para que la competencia controvertida pueda ser de titularidad autonómica, esto es, pues vienen a sostener y admitir, como ya lo hicieran en el conflicto positivo de competencia en el que recayó la STC 12/1984, que aquella expresión ha de entenderse referida a que las instalaciones estén físicamente ubicadas en el territorio de la Comunidad Autónoma, lo que así ocurre en este caso. Tampoco discrepan sobre la consideración de que la ubicación de la instalación de transporte de energía en el territorio de la Comunidad Autónoma es condición necesaria, pero no suficiente, para estimar la competencia como autonómica, ya que habrá además que examinar si su aprovechamiento afecta o no a otra Provincia o Comunidad Autónoma. El desacuerdo comienza a partir de este momento, al sostener la Letrada de la Generalidad de Cataluña que no es posible que el aprovechamiento de la instalación pueda afectar a otra Provincia o Comunidad Autónoma, mientras que para el Abogado del Estado resulta evidente la afectación del aprovechamiento en términos extracomunitarios (...). El proyecto presentado por CAMPSA a la Dirección General de Industria y Energía de la Generalidad - no cuestionado ni rebatido por el Abogado del Estado- revela que el oleoducto controvertido es de un único sentido y tiene una sola estación de bombeo cabecera, no estando técnicamente prevista en el mismo su conversión en un oleoducto de doble sentido mediante la instalación de una estación de bombeo en Barcelona para posibilitar, de este modo, el trasiego de productos desde Cataluña hacia la red general, con el conşiguiente aprovechamiento extracomunitario de la instalación. De conformidad con el mencionado proyecto, el oleoducto para cuya construcción se solicitó autorización tiene por objeto el enlace de la refinería de ENPETROL en Pobla de Mafumet (Tarragona) con las factorías de CAMPSA en el Puerto de Barcelona y en Fornells de la Selva (Girona) para el transporte de productos petrolíferos entre aquélla y éstas, estando destinados los mismos, al menos primeramente, a los usuarios afincados a la Comunidad Autónoma, lo que evidencia, en definitiva, el aprovechamiento 
intracomunitario de la instalación y, en consecuencia, la titularidad autonómica de la competencia controvertidas (vid. f.j. 7).

Fallo: Declarar que la competencia controvertida corresponde a la Comunidad Autónoma de Cataluña.

(Sentencia n..$^{\circ}$ 108/1996, de 13 de junio. Pleno. BOE 12 de julio de 1996. J. D. González Campos).

\section{D) Entidades de Crédito}

1. Conflictos positivos de competencia acumulados núms. 960 y 965 de 1987, promovidos, respectivamente, por la Generalidad Valenciana y la Generalidad de Cataluña en relación con los arts. 4, 5, 6, 9, 11 y 12 de la Orden del Ministerio de Economía y Hacienda de 3 de marzo de 1987, sobre liberalización de tipos de interés y comisiones y sobre normas de actuación de las Entidades de Depósito. En el primero de los conflictos se produce el desistimiento de la Generalidad Valenciana, y, en relación con el segundo conflicto, el TC lo desestima y declara que las disposiciones impugnadas no son contrarias al orden constitucional de distribución de competencias.

«Queda en pie el conflicto promovido por la Generalidad de Cataluña, cuya diana son los arts. 4, 5, 6 y 9, el último párrafo del 11 y el 12 de la ya citada Orden ministerial, aun cuando, antes de entrar a juzgar la controversia competencial, sea necesario indagar qué incidencia pueda haber tenido en su planteamiento la Orden del Ministro de Economía y Hacienda de 12 de diciembre de 1989 sobre tipos de interés y comisiones, normas de actuación, información a clientes y publicidad de las Entidades de Crédito, que derogó íntegramente la Orden objeto de este conflicto, sustituyéndola. En opinión del Abogado del Estado la disputa competencial ha desaparecido mientras que para la Generalidad de Cataluña, pervive (...).

En este caso ... la identidad de los fundamentos en que se asienta la pretendida inconstitucionalidad de los preceptos de una y otra norma reglamentaria - la modificación operada por la posterior norma de derogación permite mantener y reproducir en su integridad los términos en que se planteó la inicial controversia - representa una circunstancia añadida que abona la necesidad de su examen (en sentido análogo, STC 87/1993) y, por tanto, de entrar a juzgar la cuestión de fondo, el meollo de la controversia competencial planteada por la Generalidad de Cataluña» (vid. ff.jj. 2 y 3 ). 
RESEÑA DE SENTENCLAS DEL TRIBUNAL CONSTITUCIONAL ..

«Es hora ya de pasar al enjuiciamiento de los preceptos impugnados, uno a uno pero también en grupos homogéneos, el primero formado por tres de ellos, los arts. 4, 5 y 6 . Una disección analítica del conjunto, trabado entre sí, pone de manifiesto, ante todo, que explícitamente se consagra la libertad para que las Entidades de depósito determinen, por una parte, "las fechas de valoración de los cargos y abonos de sus cuentas activas y pasivas", así como los desfases máximos y mínimos de ambas a favor o en contra de la clientela, y, por la otra parte, para que fijen a su arbitrio las tarifas de las comisiones por sus operaciones o servicios (arts. 4 y 5). Es evidente que el objeto principal de esta regulación es un aspecto muy importante de la actividad bancaria, cualitativa y cuantitativamente, con reflejo directo e inmediato en la cuenta de resultados. Por tanto, no cabe negar que gira en la órbita de la ordenación del crédito y de la banca por incidir en el funcionamiento del sistema, uno de cuyos elementos es, por supuesto, el cliente. Aquí el protagonismo se reserva a las Entidades, quedando aquél en un discreto segundo plano. Lo sobredicho adquiere todo su significado si se encuadra en el marco de las Directivas de la Unión Europea que, en este ámbito, propugnan la liberalización de los servicios bancarios con el reconocimiento de las operaciones respectivas en todos sus países integrantes.

Una vez proclamada así la libertad de actuación de estas Entidades de depósito, las demás reglas que contienen las tres normas en tela de juicio, y muy especialmente la última de ellas, el art. 6 tienen un carácter cautelar, sin relieve propio, y en definitiva son instrumentales para obtener el fin previsto sin mengua del sistema. El énfasis, como se dijo, ha de ponerse en la autorregulación de estos aspectos, siendo pues accesorio que las normas donde tenga reflejo se comuniquen al Banco de España, se hagan públicas o se redacten con claridad. Las bases de la ordenación bancaria tienen una evidente dimensión normativa, con la flexibilidad formal propia de la materia cuyas características son la rapidez y discreción, pero por éstas y otras razones ajenas al caso, permiten su plasmación en actos singulares de naturaleza ejecutiva SSTC 135/1992, fundamento jurídico $3 .^{\circ}, 96 / 1984$, fundamento jurídico $4 .^{\circ}$ y $1 / 1982$, fundamento jurídico $1^{\circ}{ }^{\circ}$. Así pues, en esta modalidad encaja el registro por el Banco de España de las normas sobre fechas de valoración y de las tarifas así como su publicidad, para conocimiento general, y su inteligibilidad.

En estos dos últimos aspectos, y muy especialmente al tratar del último, cuando el art. 6 advierte que las normas "se redactarán de forma clara, concreta y fácilmente comprensible", late la preocupación de configurar una serie de garantías, todas formales por cierto, para la clientela, preocupación nunca negada, como muestra el preámbulo de la Orden ministerial. Es cierto que estos aspectos podrían ser enfocados desde la óptica de la protección del consumidor, en cuyo ámbito la Comunidad Autónoma de Cataluña tiene un papel im- 
portante, pero no lo es menos que están puestas primordialmente al servicio del buen funcionamiento del sistema bancario, cuya información, disciplina e inspección se encomienda por la Ley al Banco de España. Esta regulación tiende directamente a la transparencia de la actuación bancaria, que no es evidentemente defensa del cliente aun cuando pueda tener más de un efecto reflejo en su beneficio, jugando tanto en favor de la competencia como de aquél. Su protección, por otra parte, ha de ser ingrediente necesario de cualquier política, incluso la económica, sin que ello altere su esencia. En tal sentido la finalidad sustantiva y, por ello, principal, a la cual se orienta la disposición reglamentaria en entredicho, actúa como soporte de lo que hemos llamado en otras ocasiones el título más específico - la ordenación bancaria - respecto del otro - la protección de los consumidores-, como ya ocurrió en el caso de la sanidad (SSTC 71/1982 y 69/1988). En definitiva, la misión que corresponde al Banco de España para la comprobación y el control de la actividad bancaria como guardián del sistema, en su doble faceta de estructura-función dotan de carácter básico a su intervención para el registro previo, la publicidad y la inteligibilidad de la autorregulación de los tipos y las fechas de valoración para las operaciones de las Entidades de crédito» (f.j. 5).

«Otro grupo con evidente homogeneidad está formado por los arts. 9 y 12. El primero de ellos dice que el "Banco de España mantendrá un Servicio de Reclamaciones encargado de recibir y tramitar las que pudieran formular los clientes de las Entidades de depósito sobre las actuaciones de éstas que puedan quebrantar las normas de disciplina o las buenas prácticas y usos bancarios, en las operaciones que les afecten". Asimismo el precepto establece las normas por las que se disciplina tal Servicio. Por su parte, el art. 12 impone el deber de comunicar al Banco de España, tan pronto como se produzca, la apertura de oficinas que se efectúe en el régimen de libertad establecido en el art. 7.1 del Real Decreto 1370/1985, con independencia de que lo hagan también a la Comunidad Autónoma que hubiere asumido competencias sobre expansión; de la misma manera, las Cajas de Ahorro quedan también obligadas a poner en conocimiento del Banco de España la apertura de oficinas fuera del territorio de la Comunidad Autónoma en que tengan su sede. Finalmente, se impone la carga de comunicar los cambios de domicilio, cesiones, traspaso y cierres de oficinas.

El representante de la Comunidad Autónoma considera que, aun cuando hayan quedado a salvo sus potestades de disciplina en punto a las Cajas de Ahorro y Cooperativas de Crédito y, en consecuencia, pueda establecer su propio servicio de reclamaciones, la Generalidad de Cataluña ostenta facultades disciplinarias respecto de todas las entidades de crédito situadas en su territorio, por ser parte de la potestad ejecutiva configurada en el art. 10.1.4 EAC, que a su parecer, enervaría cuantas determinaciones se deriven, de la Ley 30/1980, o de 
RESEÑA DE SENTENCLAS DEL TRIBUNAL CONSTITUCIONAL ...

otras posteriores, opuestas a tal diseño, alegato claramente rechazable. La creación de un Servicio de Reclamaciones en nada ignora o menoscaba las competencias autonómicas, como recuerda el Abogado del Estado, si se tiene en cuenta que este instrumento se inserta con toda evidencia y naturalidad en el ámbito de las potestades disciplinarias que al Banco de España le asisten de conformidad con el orden constitucional de distribución de competencias como ya dejara sentado este Tribunal desde la STC 1/1982 (fundamento jurídico 9.).

Tampoco puede prosperar la pretendida invasión competencial que se le reprocha a la obligación impuesta por el art. 12 de la tan citada Orden de 3 de marzo de 1987 de comunicar al Banco de España la apertura de oficinas tan pronto como se produzca, con independencia de que lo hagan también a la Comunidad Autónoma. En efecto, este deber de comunicación -que tampoco puede disociarse artificialmente de la libertad de apertura establecida en el art. 7.1 del Real Decreto 1370/1985, como el propio art. 12 de la Orden de 3 de marzo de 1987 se encarga de subrayar - ha de entenderse amparado por el concepto de bases ex art. 149.1.11 CE, mantenido en constante jurisprudencia. En tal sentido, el conocimiento de la apertura de oficinas es una cuestión que aparece vinculada a la solvencia de la Entidad de depósito y, por consiguiente, conecta con las potestades de vigilancia del sistema financiero que son inherentes al Banco de España, en los términos antes indicados. También ha de recordarse que la STC 178/1992 declaró la conformidad constitucional de los arts. 2.2, $2.5,5.2,6$ y 7.3 del Real Decreto $1370 / 1985$ desde el punto de vista competencial, preceptos que, además de atribuir al Banco de España potestades y funciones en el plano ejecutivo de mayor envergadura que la configurada en el art. 11, guardan igualmente una clara conexión lógica con la materia objeto de nuestras reflexiones» (f.j. 6).

«Para terminar, el inciso final del art. 11 de la Orden de 3 de marzo de 1987, dispuso que "los dividendos, aplicaciones o retornos cooperativos a cuenta no podrán anunciarse ni hacerse efectivos hasta que el Banco de España haya tenido conocimiento suficiente de los resultados del período a que se refieren; todo ello sin perjuicio, en su caso, de lo previsto en el párrafo primero del art. 107 de la Ley de Sociedades Anónimas".

Este precepto, como queda reflejado en la remisión expresa que lucía en su primer párrafo, enlaza con el Real Decreto 1370/1985, sobre recursos propios de las Entidades de Depósito, por el que se desarrollaba el Título II de la Ley $13 / 1985$, sobre coeficientes de inversión, recursos propios y obligaciones de información de los intermediarios financieros (cfr. núm. B anterior). Pues bien, esta materia ha sido ya objeto de enjuiciamiento por este Tribunal, en la STC $178 / 1992$, en la que, a nuestro propósito y en lo que hace al precepto aquí considerado, se reitero la doctrina sentada, entre otras, en la STC 135/1992, afir- 
mándose que todas esas funciones que se le reconocen al Banco de España "están directamente vinculadas a las condiciones de solvencia y cumplimiento de las normas de control y disciplina que deben observar las Entidades de Depósito". La obligación de comunicación que contempla el art. 12 está directamente vinculada, en efecto, a la política de solvencia de las Entidades de Crédito y, en consecuencia, no se produce extralimitación alguna, ni vulneración de la competencia que a la Generalidad le reserva el art. 10.1.4. ${ }^{\circ}$ del EAC (en sentido análogo, STC 178/1992). Más en concreto, la regulación que tal inciso contenía puede quedar incluida entre los aspectos ejecutivos encuadrables dentro de la competencia estatal sobre las bases de la ordenación del crédito a la cual se refiere la STC 178/1992 (fundamento jurídico 2, in fine)» (f.j. 7).

Fallo: 1. Tener por desistido al Consejo de Gobierno de la Generalidad Valenciana del conflicto positivo de competencia núm. 960/87, planteado en relación con los arts. 9 y 11 de la Orden del Ministerio de Economía y Hacienda de 3 de marzo de 1987, sobre liberalización de tipos de interés y comisiones y sobre normas de actuación de las entidades de depósito.

2. Desestimar el conflicto de competencia núm. $965 / 1987$, promovido por la Generalidad de Cataluña, y, en su virtud, declarar que las disposiciones impugnadas no son contrarias al orden constitucional de distribución de competencias.

(Sentencia n..$^{\circ}$ 155/1996, de 9 de octubre. Pleno. BOE 5 de noviembre de 1996. R. de Mendizábal Allende. Voto particular formulado por C. Viver PiSunyer).

\section{E) Transportes Terrestres}

1. Recursos de inconstitucionalidad, acumulados, núms. 1191/1987, 1390/1987, 1391/1987, 1392/1987 y 1393/1987, interpuestos, respectivamente, por el Presidente del Gobierno contra determinados preceptos de la Ley 12/1987, de 25 de mayo, del Parlamento de Cataluña, sobre regulación del Transporte de Viajeros por Carretera mediante vehículos de motor; por el Consejo Ejecutivo de la Generalidad de Cataluña contra la totalidad, con excepción de determinados artículos, de la Ley 16/1987, de 30 de julio, de Ordenación de los Transportes Terrestres; por el Consejo Ejecutivo de la Generalidad de Cataluña contra determinados artículos de la Ley Orgánica 5/1987, de 30 de julio, de Delegación de facultades del Estado en las Comunidades Autónomas, en relación con los Transportes por carretera y por cable; por el Parlamento de Cataluña contra determinados artículos de la Ley 16/1987, de 30 de julio, de Ordenación de los 
RESEÑA DE SENTENCIAS DEL TRIBUNAL CONSTITUCIONAL ..

Transportes Terrestres; y, por último, por el Parlamento de Cataluña contra determinados artículos de la Ley Orgánica 5/1987, antes citada. El Tribunal estima parcialmente los recursos y declara la inconstitucionalidad y, por consiguiente, la nulidad de determinados preceptos, así como el carácter básico y la conformidad al orden constitucional de competencias de otras.

Vid. supra. Fuentes: Supletoriedad del Derecho estatal.

Fallo: A) En cuanto a las impugnaciones relativas a la Ley estatal 16/1987, de Ordenación de los Transportes Terrestres, deducidas por el Parlamento y el Consejo Ejecutivo de la Generalidad de Cataluña, estimar parcialmente los recursos y, en consecuencia:

1. Declarar inconstitucionales $y$, por consiguiente nulos el inciso segundo del párrafo primero y el párrafo segundo del art. 2, los arts. 113 a 118 y la Disposición transitoria décima.

2. Declarar que son básicos los arts. 3; 4; 12.1; 72.1, párrafo segundo; 75.3, párrafo primero; el apartado $5 .^{\circ}$ de la Disposición transitoria segunda y los apartados primero, cuarto, sexto y noveno de la Disposición transitoria quinta, interpretada en los términos que se expresan en el fundamento jurídico 53.

3. Declarar que no son básicos los arts. 12.2 (en el inciso que establece que la actuación pública «se sujetará a lo establecido en esta Ley para cada modo o clase de transporte»); $16.1 ; 36.5 ; 42 ; 43 ; 44 ; 45$ y 46; 59; 64.2; 75.3, párrafo segundo; $80.2 ; 81.1$ y $2 ; 83.1 ; 93.2 ; 95.2 ; 102.2$ b); $110.2 ; 155.2$, entendido en los términos que se expresan en el fundamento jurídico $44,157.2$ a), $158.2,179.6$ y 188 .

4. Declarar básico, y, por consiguiente, aplicable a los transportes intrautonómicos competencia de la Comunidad Autónoma recurrente, el art. 14, interpretando la referencia que se efectúa a los motivos sanitarios en los términos expuestos en el fundamento jurídico 14 y exceptuando el último inciso — «u otras causas graves de utilidad pública e interés social que igualmente lo justifiquen»-, que se declara contrario al orden constitucional de competencias y, por consiguiente, nulo.

5. Declarar básico, y, por consiguiente, aplicable al ámbito de los transportes que sean competencia de la Comunidad Autónoma recurrente, el art. 31, último párrafo, en la medida en que establece la colaboración del Estado en la homologación de los Planes Territoriales y Especiales y declarar que dicho precepto no es básico en cuanto establece la necesaria colaboración del Estado 
en la elaboración de dichos planes, según lo expuesto en los fundamentos jurídicos 20 y 21.

6. Declarar que el art. 71.2 es básico, excepto en su último inciso, en los términos expuestos en el fundamento jurídico 30 .

7. Declarar que el art. 124 vulnera la distribución constitucional de competencias entre el Estado y la Comunidad Autónoma recurrente, por lo que no es aplicable en Cataluña.

8. Declarar que son conformes al orden constitucional de competencias: el art. 5.1, entendido como se expone en el fundamento jurídico 15; el art. 6, interpretado en la forma que se expresa en el fundamento jurídico 16; el art. 7, interpretado en la forma expuesta en el fundamento jurídico 17; el art. 13, interpretado en la forma expuesta en el fundamento jurídico 13 ; los arts. 25 y 26 , en tanto se entiendan como se dice en el fundamento jurídico 18; el art. 29.2, interpretado en la forma expuesta en el fundamento jurídico 19; el art. 38.4, entendido en la forma relatada en el fundamento jurídico 23; los arts. 47.1 y $52.1 \mathrm{c})$, entendidos del modo expuesto en el fundamento jurídico 26 ; los arts. 91.1 y 2 , interpretados en la forma a que se hace referencia en el fundamento jurídico $34 ; \mathrm{y}$, finalmente, el art. 154 , interpretado como se expresa en el fundamento jurídico 43.

9. Desestimar los recursos en todo lo demás.

B) En cuanto a las impugnaciones relativas a la Ley Orgánica 5/1987, de delegación de facultades del Estado en materia de transportes, estimar parcialmente los recursos interpuestos por el Consejo Ejecutivo de la Generalidad y por el Parlamento de Cataluña y, en consecuencia:

1. Declarar conformes al orden constitucional de competencias los arts. 3.3, 5 y 13 , interpretados, respectivamente, conforme a lo expuesto en los fundamentos jurídicos 58,59 y 60 .

2. Declarar inconstitucional y nulo el art. 20.

3. Desestimar los recursos en todo lo demás.

C) En cuanto a la Ley $12 / 1987$, del Parlamento de Cataluña, sobre transportes de viajeros por carretera con vehículos de motor, estimar parcialmente el recurso interpuesto por el Presidente del Gobierno y, en consecuencia:

1. Declarar inconstitucionales y, por consiguiente, nulos los arts. 2, 42.6, 53 b) y c) y $54 \mathrm{e}$ ). 
RESEÑA DE SENTENCLAS DE. TRIBUNAL CONSTITUCIONAL ...

2. Desestimar el recurso en todo lo demás.

(Sentencia n. ${ }^{\circ} 118 / 1996$, de 27 de junio. Pleno. BOE 29 de julio de 1996. T. S. Vives Antón. Voto particular formulado por M. Jiménez de Parga y Cabrera).

\section{F) Publicidad}

1. Recurso de inconstitucionalidad núm. 308/1989 promovido por el Gobierno Vasco, contra la Ley 34/1988, de 11 de noviembre, General de Publicidad, en cuanto no excluye la aplicación directa de sus preceptos en el ámbito de la Comunidad Autónoma. Los alegatos de la representación de la parte actora se dirigen exclusivamente a intentar la demostración del exceso competencial en el que habría incurrido el legislador estatal al plasmar en el Título IV de la Ley (arts. 25 a 33) la opción por un sistema o procedimiento jurisdiccional, en vez de administrativo, para el control de la publicidad ilícita, sin prever cláusula alguna que excepcione la aplicabilidad de dicha regla en la Comunidad Autónoma actora, que ha asumido competencia exclusiva en materia de publicidad en colaboración con el Estado (art. 10.27 EAPV). El Tribunal Constitucional desestima el recurso por entender que la Ley impugnada, y especialmente su articulo 28 al residenciar en los órganos jurisdiccionales ordinarios las controversias derivadas de la publicidad ilícita delimita o enmarca la competencia de los mismos, estableciendo asi una regla de competencia jurisdiccional, cuya determinación corresponde en exclusiva al legislador estatal ex art. 149.1.6. ${ }^{\circ} \mathrm{CE}$.

«El grupo de preceptos impugnados - arts. 25 a 28 - forma parte del Título IV de la Ley, el cual lleva por rúbrica "De la acción de cesación y rectificación y de los procedimientos". En él se recoge, según la Exposición de Motivos, una de las innovaciones más relevantes que introduce el legislador estatal en la ordenación del sector de la publicidad, al decantarse por una opción distinta a la contemplada en el Estatuto de la Publicidad de 1964, en el que se atribuía a un órgano administrativo, el Jurado Central de Publicidad, la competencia para entender de las cuestiones derivadas de la actividad publicitaria. Tal opción se plasma en el art. 28 de la Ley, precepto en el que la Comunidad Autónoma actora centra su pretensión impugnatoria, que atribuye a los organos de la jurisdicción ordinaria el conocimiento de las controversias derivadas de la publicidad ilícita, las cuales se tramitarán, según dispone el art. 29, conforme a lo establecido por la Ley de Enjuiciamiento Civil para los juicios de menor cuantía, con las peculiaridades que se recogen en el mencionado artículo, tendentes a adaptar la actividad judicial a las particularidades del fenómeno 
publicitario. En la vía judicial que instaura la Ley, y en tal sentido ha de entenderse el alcance de las controversias a las que se refiere el art. 28, sólo cabe deducir como pretensión principal, sin perjuicio de que puedan acumularse pretensiones derivadas de la misma actividad publicitaria del anunciante cuando por su naturaleza o cuantía no sean incompatibles entre sí (art. 33), la cesación o rectificación de la actividad publicitaria difundida cuando se considere ilícita, cuyo ejercicio resulta compatible con el de las acciones civiles, penales, administrativas o de otro orden que correspondan y con la persecución y sanción como fraude de la publicidad engañosa por los órganos administrativos competentes en materia de protección y defensa de los consumidores y usuarios (art. 32). Por su parte, el art. 25 determina los sujetos legitimados activamente para entablar las acciones de cesación o rectificación frente al anunciante, único sujeto publicitario legitimado pasivamente, y establece como requisito previo al ejercicio judicial de dichas acciones la solicitud al anunciante de la cesación o rectificación voluntaria de la publicidad entendida como ilícita, cuya manera de realizarla regulan, respectivamente, los arts. 26 y 27.

En el Título IV de la Ley, en el que se ubican los preceptos impugnados, se plasma, por consiguiente, la opción del legislador estatal (de entre los dos criterios procedimentales - jurisdiccional o administrativo- por los que alternativamente se pronuncia la Directiva 84/450/CEE, generalizando sus previsiones respecto a la publicidad engañosa a todas las clases de publicidad ilícita), por la vía judicial como cauce para el ejercicio de las acciones de cesación y rectificación. No cabe duda de que las normas recurridas, que configuran un único bloque normativo con el resto de los preceptos contenidos en el referido Título, se insertan en el ámbito de la legislación procesal, pues la implantación o establecimiento de un sistema o mecanismo jurisdiccional como medio de resolución de las controversias derivadas, en este caso, del desarrollo de la actividad publicitaria, mediante el cual las partes pueden obtener una decisión que ponga fin a los conflictos surgidos, es materia propia de la legislación procesal, reservada al Estado con carácter exclusivo por el art. 149.1.6. ${ }^{\circ}$ $\mathrm{CE}$, cuya atribución "responde a la necesidad de salvaguardar la uniformidad de los instrumentos jurisdiccionales" (SSTC 71/1982, fundamento jurídico 20; $83 / 1986$, fundamento jurídico $2 .^{\circ} ; 123 / 1988$, fundamento jurídico $3 .^{\circ}$ ). En este sentido, no es ocioso recordar que el Tribunal Constitucional ya tuvo ocasión de declarar en relación con el establecimiento de un sistema de arbitraje, que, en tanto que equivalente jurisdiccional, a través del cual se pueden obtener los mismos objetivos que con la jurisdicción civil, era materia propia de la legislación procesal civil (art. 149.1.6. ${ }^{\circ} \mathrm{CE}$ ), relacionada, en cuanto a los efectos del laudo arbitral y al sistema de recursos, con la Administración de Justicia (SSTC 15/1989, fundamento jurídico $9 .^{\circ}$ b; 62/1991, fundamento jurídico $\left.5 .^{\circ}\right)$. 
RESENA DE SENTENCIAS DE TRIBUNAL CONSTTTUCIONAL ..

No resulta distinto el encuadramiento desde el punto de vista competencial de los preceptos impugnados considerados individualmente en atención a sus enunciados. En efecto, el art. 28, en el que la Comunidad Autónoma actora centra su pretensión impugnatoria, al residenciar en los órganos jurisdiccionales ordinarios las controversias derivadas de la publicidad ilícita delimita o enmarca la competencia de los mismos, esto es, establece una regla de competencia jurisdiccional, cuya determinación corresponde en exclusiva al legislador estatal ex art. 149.1.6. ${ }^{\circ}$ CE (SSTC 159/1991, fundamento jurídico $4 . .^{\circ} ; 121 / 1992$, fundamento jurídico $\left.4 .^{\circ}\right)$. El art. 25 en cuanto, de un lado, determina los sujetos legitimados activa y pasivamente y, de otro, establece la solicitud de cesación y rectificación como requisito previo para entablar ambas acciones en vía judicial, así como los arts. 26 y 27 al disciplinar la forma en que ha de realizarse dicha solicitud contienen una regulación de naturaleza jurídico-procesal, por lo que es evidente su inserción en el indicado título competencial (SSTC 71/1982, fundamento jurídico $20 ; 83 / 1986$, fundamento jurídico $2 .^{\circ} ; 123 / 1988$, fundamento jurídico $3 .^{\circ}$ ).

Cuanto antecede conduce a rechazar las pretensiones deducidas en este proceso constitucional por el Gobierno Vasco, al no apreciarse la extralimitación competencial denunciada ni menoscabo de competencia autonómica alguna.

Fallo: Desestimar el presente recurso de inconstitucionalidad.

(Sentencia n..$^{\circ}$ 146/1996, de 19 de septiembre. Pleno. BOE 21 de octubre de 1996. M. Jiménez de Parga y Cabrera).

\section{TRÁFICO, CIRCULACIÓN DE VEHÍCULOS Y SEGURIDAD VIAL}

1. Conflicto positivo de competencia núm. 433/1988 promovido por el Gobierno de la Nación respecto del art. 2, in fine, y Anexo de la Orden del Departamento de Industria y Comercio del Gobierno vasco, de 2 de abril de 1987 por la que se regula la Inspección Técnica a Vehículos dedicados a Transporte Escolar y de Menores, en tanto en cuanto adicionan a la normativa estatal vigente determinados requisitos relativos a aquellas normas técnicas. Se alega que la competencia en la materia pertenece al Estado, en virtud del art. 149.1.21 CE, que atribuye al Estado la competencia exclusiva sobre tráfico y circulación de vehículos a motor. El TC declara que la titularidad de la competencia controvertida corresponde al Estado y, por tanto, la nulidad de las disposiciones recurridas.

«Debe acogerse la argumentación del Abogado del Estado, como ya manifestamos en la STC 59/1985 y, posteriormente, en la STC 181/1992. En el con- 
cepto de tráfico y circulación de vehículos a motor, como materia atribuida por el art. 149.1.21 CE a la competencia exclusiva del Estado, "no se encuentran englobadas solamente las condiciones atinentes a la circulación (vgr., señales, limitaciones de velocidad, etc.), sino las condiciones que deben cumplir los vehículos que circulan". De ahí, que no quepa separar, como integrantes de esas garantías de seguridad, los requisitos técnicos que debe reunir un vehículo para garantizar la seguridad de personas y cosas exteriores a él, de aquellos requisitos que pretenden proteger a quienes, como conductores o pasajeros, se encuentren en su interior. "Ambas dimensiones son elementos indisolubles de la seguridad del tráfico y circulación, pues es innegable la repercusión que un accidente o fallo de seguridad en el interior de un vehículo, que afecte a las personas que en él viajan (tanto conductor como pasajeros) puede tener en la conducción del mismo, así como en otros vehículos de su entorno" (STC $181 / 1992$, fundamento jurídico $3 .^{\circ}$ ).

La conclusión no puede ser ahora distinta de la que allí se dedujo: La regulación de los requisitos técnicos destinados a la protección y seguridad de conductores y viajeros debe entenderse incluida en la reserva a la competencia estatal exclusiva del art. 149.1.21 CE. Y como materia sujeta a tal competencia exclusiva, no cabe la intervención, al respecto, de las Comunidades Autónomas, modificando o desarrollando las prescripciones estatales» (vid. f.j. 2).

«Los preceptos de la Orden del País Vasco que se impugnan se dictan con invocación explícita de la competencia exclusiva que tiene reconocida esta Comunidad Autónoma en materia de industria y en ejecución de los requisitos técnicos establecidos en el Real Decreto 2296/1983 con el objeto de conseguir los máximos niveles de seguridad para el tipo de transporte de escolares y de menores. Sin embargo, el mandato contenido en el art. 2, in fine, de la misma en relación con su Anexo, se refiere claramente a requisitos de innegable repercusión en la seguridad vial, pues afectan no solamente a la seguridad de las personas que utilizan el transporte (puertas automáticas, ventanas), sino también a la seguridad del conductor (regulación de pantallas de protección). Se inscriben, así, plenamente, en el ámbito de la seguridad de la circulación y el tráfico, según lo ya expuesto. Por ello ha de concluirse, accediendo a las pretensiones formuladas por el Abogado del Estado, que invaden la competencia reservada al Estado por el art. 149.1.21 CE» (f.j. 3).

Fallo: 1. Que corresponde al Estado la titularidad de la competencia controvertida.

2. La nulidad del art. 2, in fine, y anexo de la Orden del Departamento de Industria y Comercio del Gobierno vasco, de 2 de abril de 1987, por la que se 
RESEÑA DE SENTENCIAS DEL TRIBUNAL CONSTTTUCIONAL ...

regula la Inspección Técnica de Vehículos dedicados al transporte escolar y de menores.

(Sentencia n. ${ }^{\circ}$ 183/1996, de 14 de noviembre. Pleno. BOE 17 de diciembre de 1996. C. Viver Pi-Sunyer).

\section{CULTURA}

1. Conflicto positivo de competencia núm. 2390/1989, promovido por el Consejo Ejecutivo de la Generalidad de Cataluña, frente a los apartados primero, cuarto, quinto y sexto de la Orden del Ministerio de Cultura, de 10 de julio de 1989 (RCL 1989/1671), por la que se regulan las subvenciones y ayudas económicas a los museos e instituciones que integran mediante convenio con el Ministerio de Cultura el Sistema Español de Museos. El Tribunal declara que la competencia controvertida corresponde a la Comunidad Autónoma de Cataluña puesto que los preceptos impugnados, al atribuir al Estado facultades para proponer y conceder las subvenciones $y$ para canalizar las solicitudes y especificar la documentación que debe acompañarlas, vulneran el orden de competencias constitucionalmente establecido.

«El Estado puede, sin duda, consignar subvenciones de fomento en sus Presupuestos Generales en materia de museos de titularidad de la Generalidad de Cataluña y especificar de forma "global o genérica" su afectación o destino (STC 13/1992, fundamento jurídico $7^{\circ}$ ), pero no puede reservarse competencias de gestión salvo que se trate de uno de los casos excepcionales en los que la misma deba llevarse a cabo de forma centralizada. Ninguna de las alegaciones vertidas en el presente Conflicto positivo de competencia permite concluir que la gestión de los fondos controvertidos tenga que ser centralizada en órganos estatales y no encomendada a las Comunidades Autónomas. En consecuencia, debe afirmarse que los preceptos examinados, al atribuir al Estado facultades para proponer y conceder las subvenciones (aps. 1, 5 y 6) y para canalizar las solicitudes y especificar la documentación que debe acompañarlas (ap. 4), vulneran el orden de competencias constitucionalmente establecido» (f.j. 6).

Fallo: Declarar que la competencia de gestión controvertida corresponde a la Comunidad Autónoma de Cataluña.

(Sentencia n. $109 / 1996$, de 13 de junio. Pleno. BOE 12 de julio de 1996. C. Viver Pi-Sunyer). 
REALA 273 (ENERO-ABRIL, 1997)

\section{UNIVERSIDADES}

1. Conflicto positivo de competencia núm. 1715/1991, promovido por el Consejo Ejecutivo de la Generalidad de Cataluña en relación con el art. 1 y la Disposición adicional primera del Real Decreto 557/1991, de 12 de abril (BOE núm. 95, de 20 de abril), sobre creación y reconocimiento de Universidades y Centros universitarios, en cuanto califican como normas básicas los siguientes preceptos del citado Real Decreto: el art. 5.1 (en lo que se refiere a la expresión «no menos de tres impartirán el segundo ciclo y, al menos, una de éstas, de Ciencias Experimentales o estudios técnicos»); el art. 7.1, 4 y 5 (excepto su primera frase); el art. 9, en relación con el Anexo en sus apartados 2 (excepto su primera frase), 5 (excepto su inciso «El Campus estará dotado de instalaciones deportivas y de los servicios complementarios precisos») y 6; art. 10, art. 11, art. 16.5 y art. 18.2 (en su referencia al Ministerio de Educación y Ciencia). El TC estima parcialmente el conflicto y entiende que no son normas básicas y que corresponden a la Generalidad de Cataluña las competencias ejercidas en el inciso «y, al menos, una de éstas, de Ciencias Experimentales o estudios técnicos» del art. 5.1 y en los arts. 9 (en relación con los incisos de los apartados 2, 5 y 6 del Anexo objeto de impugnación) y 18. 2 (en cuanto a la mención que en él se hace al Ministerio de Educación y Ciencia).

«El art. 5.1 del Real Decreto 557/1991 dispone que "las Universidades públicas o privadas deberán contar, respectivamente, con los Departamentos o la estructura docente necesaria para la organización y desarrollo de enseñanzas conducentes, como mínimo, a la obtención de ocho títulos de carácter oficial que acrediten enseñanzas de Diplomatura, Arquitectura Técnica, Ingeniería Técnica, Licenciatura, Arquitectura o Ingeniería, de las cuales no menos de tres impartirán el segundo ciclo y,al menos, una de éstas, de Ciencias Experimentales o estudios técnicos". A juicio del Consejo Ejecutivo, la imposición de que no menos de tres enseñanzas impartan el segundo ciclo $y$, al menos, una de ellas lo sea de Ciencias Experimentales o estudios técnicos excede del contenido material de las normas básicas para el desarrollo del art. $27 \mathrm{CE}$ y establece unos requisitos en el nivel estrictamente organizativo que tampoco pueden tener cobertura como complemento necesario de los arts. 5.3 y 58.2 de la LO 11/1983, de Reforma Universitaria. Entiende el Consejo Ejecutivo que la LO 11/1983 sólo ha previsto que el Gobierno puede determinar con carácter general el número de Centros necesarios para el comienzo de las actividades de las nuevas Universidades, por lo que nada se objeta a que se haya fijado ese número en un mínimo de Departamentos necesarios para la organización y desarrollo de las enseñanzas o que éstas se refieran a ciclos completos; pero la determinación, además, del nivel de tales enseñanzas o la circunstancia de que al menos 
RESEN̂A DE SENTEACLAS DER TRIBUNAL CONSTTUCIONAL ..

una deberá referirse a Ciencias Experimentales o estudios técnicos es una precisión que a todas luces excede de lo previsto en la LO 11/1983. El número de Centrơs o de las distintas enseñanzas que se impartan en una Universidad o el nivel de las mismas en nada afecta ni a las condiciones para la obtención, expedición y homologación de títulos ni a los aspectos básicos del desarrollo del derecho a la educación. Además, la exigencia de ese requisito no reúne ninguna de las condiciones necesarias para que una disposición general pueda tener la consideración de norma básica, pues el mandato contenido en el precepto no forma parte del común denominador normativo con que el Estado pretende conformar el modelo de Universidad en España, ya que se trata de un requisito que no se exigirá como condición mínima a todas las Universidades, sino sólo a las nuevas, es decir, a las que se reconozcan o a las que se creen a partir de este momento.

Entiende el Abogado del Estado, por el contrario, que es esencia de la Universidad que en ella se impartan titulaciones tanto experimentales como no experimentales y tanto de primer como de segundo ciclo, por lo que, de acuerdo con las facultades atribuidas al Gobierno por la Ley de Reforma y con lo establecido en el art. 149.1.1 y $30 \mathrm{CE}$, los requisitos del art. 5.1 son básicos y no estrictamente organizativos. De lo contrario, cabria la posibilidad de Universidades con enseñanzas de primer ciclo exclusivamente, con lo que se desnaturalizaría el concepto de Universidad. Los mínimos fijados no impiden, para el Abogado del Estado, que pueda configurarse un modelo propio de Universidad, sino que pueden crearse Universidades con orientaciones no sólo distintas, sino incluso básicamente antitéticas.

Respecto de la exigencia de que al menos tres títulos lo sean de segundo ciclo debe coincidirse con el Abogado del Estado en su carácter básico. Desde la competencia para establecer las bases en materia de enseñanza superior, el Estado puede prever no sólo el número mínimo de enseñanzas que deben impartir las Universidades, sino también el nivel mínimo que deben tener estas titulaciones, puesto que de este modo se garantiza un mínimo común denominador en nivel de la enseñanza de todas las Universidades.

Por el contrario, esta exigencia no puede extenderse a la previsión de que al menos una de las enseñanzas debe ser de ciencias experimentales o estudios técnicos. El carácter técnico, experimental, social o humanístico de las enseñanzas universitarias no condiciona la calidad docente o investigadora de la Universidad, ni "el nivel de desarrollo académico y organizativo suficiente (...) para poder asumir en su caso, la responsabilidad de convertirse en Universidad" —en palabras del preámbulo del Real Decreto aquí enjuiciado-. La calidad y la viabilidad de las Universidades la garantiza el Estado mediante, entre otros mecanismos, la homologación de estudios, títulos y denominaciones, el 
establecimiento de requisitos que debe cumplir el profesorado o determinadas exigencias materiales y organizativas. Pero, establecidas estas condiciones básicas, la decisión sobre el tipo concreto de enseñanzas o titulaciones que deben impartirse está en función de las específicas necesidades sociales y demás circunstancias particulares que concurren en cada momento y lugar y, por ello, en el ámbito territorial de las Comunidades Autónomas con competencia plena en la materia, les corresponde a ellas valorarlas en cada caso» (f.j. 4).

«De conformidad con lo dispuesto en el art. 9, las Universidades y sus Centros de nueva creación han de contar, como mínimo, con los espacios y superficies que figuran en el Anexo, de acuerdo con el tipo de enseñanzas y el número de alumnos. Varias disposiciones de ese Anexo exceden, para el Consejo Ejecutivo, del contenido material de las bases que puede fijar el Estado. Concretamente, incurren en exceso las previsiones del apartado 2 (excepto su primera frase), el apartado 5 (excepto su inciso "El Campus estará dotado de instalaciones deportivas y de los servicios complementarios precisos") y el apartado 6, pues ninguna de estas disposiciones se refiere a elementos que puedan encajar en la reserva del art. 149.1.30 CE. Entiende el Consejo Ejecutivo que, en realidad, el horario mínimo de funcionamiento del servicio de biblioteca, el número de deportes que puedan practicarse en las instalaciones deportivas o si a éstas ha de poder acceder el alumnado o también el profesorado y personal no docente, la existencia del servicio de comedor y cafetería, etc., son cuestiones que están muy alejadas de la garantía básica del derecho a la educación y nada tienen que ver, tampoco, con los títulos oficiales.

Entiende el Abogado del Estado, por su parte, que en relación con las exigencias establecidas en relación con las Bibliotecas se ha optado por imponer unos requisitos mínimos que garanticen no sólo su utilización simultánea por parte de un porcentaje determinado de alumnos, sino también unas condiciones mínimas de instalaciones y de horario que garanticen la calidad de la Biblioteca. El horario, concretamente, se basa en la combinación del número de alumnos y él número de horas que se entiende adecuado para garantizar su eficacia. En lo que a instalaciones deportivas se refiere, el Abogado del Estado no considera suficiente que el Real Decreto se limite a establecer que la Universidad estará dotada de instalaciones deportivas y de los servicios complementarios precisos, pues todos los contenidos en la norma se justifican como exigencia mínima de calidad en uno de los aspectos de la formación que deben proporcionar las Universidades. A la Generalidad le queda margen suficiente para regular determinadas materias, como la de concretar qué deportes han de ser estimados "de mayor demanda en su ámbito". De otro lado, el número de deportes viene determinado en los módulos aprobados por el Consejo Superior de Deportes (Acuerdo de 19 de julio de 1989). Por último, y en lo que afecta a los servicios comunes, se fija un mínimo que se considera imprescindible para la 
RESENA DE SENTENCLAS DE. TRIBU:AaL CONSTTUUCIONAi ..

vida universitaria y su adecuado funcionamiento, sin que se impida por ello que la Generalidad establezca otros.

El apartado 2 del Anexo dispone, en su primera frase, que el edificio o los servicios de biblioteca han de permitir, en su conjunto, la utilización simultánea de, al menos, un $10 \%$ del número total de alumnos previstos. El Consejo Ejecutivo admite que tal previsión resulta encuadrable en el concepto de lo básico y, en consecuencia, no la impugna. Sí discute, por el contrario, que puedan encuadrarse en aquel concepto las exigencias relativas a que la biblioteca cuente con salas de lectura, archivo y sistemas de préstamo y a que se garantice el uso de, al menos, cincuenta y cinco horas semanales, así como el número de volúmenes necesario para el correcto desarrollo de las enseñanzas y su uso en soporte no convencional y el de las principales revistas científicas de cada campo del saber en el ámbito de dichas enseñanzas. Y lleva razón el Consejo Ejecutivo al sostener que estas últimas exigencias exceden notoriamente del campo de lo básico. El Estado puede, en ejercicio de su competencia para la normación de lo básico, disponer que las Universidades a que se refiere el Real Decreto 557/1991 han de disponer de un servicio de biblioteca; pero, más allá de esa previsión, regular aspectos tales como el número de horas de utilización del servicio, la existencia de salas de lectura, archivo y sistema de préstamo, supone una labor de concreción normativa que excede de lo materialmente básico.

Lo mismo cabe decir en relación con el apartado 5 del Anexo, pues en él, después de exigirse la existencia de instalaciones deportivas y de los servicios complementarios precisos, se abunda hasta casi la extenuación en el desarrollo normativo de la materia, precisando el número mínimo de deportes cuya práctica ha de quedar garantizada. Si aquella primera previsión no puede sino calificarse de incardinable en el ámbito de lo básico, las que le siguen exceden, por su detalle, dicho ámbito hasta invadir la competencia autonómica cuya infracción aquí se ha denunciado.

También el apartado 6 del Anexo incurre en vicio de incompetencia, pues la prestación de servicios comunes tales como los de comedor y cafetería, información, informático y médico-asistencial, así como la existencia de un salón de actos, constituyen elementos que, sin pretender aquí restarles su importancia, no es posible considerar básicos de la institución universitaria, pues no puede adivinarse - más que, si acaso, remotamente - su conexión con el desarrollo del derecho a la educación o con la regulación de las condiciones de obtención, expedición y homologación de títulos académicos y profesionales» (f.j. 8).

«Por último, el art. 18.2 establece que el expediente de autorización de Centros extranjeros requerirá el informe del Ministerio de Educación y Cien- 
cia, así como el de Asuntos Exteriores sobre la conveniencia de la misma basada en la existencia de tratados o convenios internacionales suscritos por España y, en su defecto, en el principio de reciprocidad. Para el Consejo Ejecutivo, la referencia al Ministerio de Educación y Ciencia supone una invasión competencial en la medida en que esa es una función en el nivel ejecutivo que sólo puede corresponder a la Generalidad. Opone el Abogado del Estado, por su parte, que el texto de esta disposición no debe interpretarse en el sentido de que el informe ministerial ha de recaer sobre el cumplimiento o incumplimiento por los Centros de los requisitos fijados en el Real Decreto - que es una cuestión que corresponde a las Comunidades Autónomas competentes-, sino en el sentido de que la intervención del Ministerio, que complementa la del Ministerio de Asuntos Exteriores, y que no tiene carácter vinculante, ha de recaer, de forma exclusiva, sobre la conveniencia de la autorización basada en el contenido de los Tratados o Convenios internacionales suscritos por España y, en su defecto, en el principio de reciprocidad.

Nada cabe oponer - tampoco lo hace el Consejo Ejecutivo- a la función informativa atribuida al Ministerio de Asuntos Exteriores, subsumible en el ejercicio de la competencia reservada al Estado en el art. 149.1.30 CE. Por el contrario, el informe del Ministerio de Educación y Ciencia, que, lógicamente, habrá de referirse a la conveniencia de la autorización desde el punto de vista estrictamente educativo y académico, no se justifica en los supuestos en que el Centro cuyo establecimiento se pretende haya de radicarse en el territorio de una Comunidad Autónoma con competencias en materia de enseñanza universitaria, como es el caso con la Generalidad de Cataluña. Salvaguardada la competencia estatal en el marco de las relaciones internacionales, el informe relativo a la conveniencia de la autorización desde el punto de vista académico deberá ser evacuado por el Departamento de la Administración competente» (f.j. 12).

Vid. supra. Fuentes. Normas básicas.

Fallo: 1. Declarar que corresponden al Estado las competencias ejercidas en el inciso «de las cuales no menos de tres impartirán el segundo ciclo» del art. 5.1 y los arts. 7.1, 4 y 5; 10 a); 11 a) y 16.5 del Real Decreto 557/1991, de 12 de abril, sobre creación y reconocimiento de Universidades y Centros universitarios.

2. Declarar que no son básicas y corresponden a la Generalidad de Cataluña las competencias ejercidas en el inciso «y, al menos, una de éstas, de Ciencias Experimentales o estudios técnicos» del art. 5.1 y en los arts. 9 (en relación con los incisos de los apartados 2, 5 y 6 del Anexo objeto de impugna- 
RESEÑA DE SENTENCIAS DE TRIBUNAL CONSTITUCIONAL ..

ción) y 18.2 (en cuanto a la mención que en él se hace al Ministerio de Educación y Ciencia).

3. Declarar la nulidad del art. 1 y de la Disposición adicional primera en cuanto considera básicos los preceptos mencionados en el anterior pronunciamiento.

(Sentencia n..$^{\circ}$ 131/1996, de 11 de julio. Pleno. BOE 12 de agosto de 1996. C. Viver Pi-Sunyer. Voto particular formulado por J. D. González Campos, al que se adhiere M. Jiménez de Parga y Cabrera). 
